\title{
Partial Derivative Fitted Taylor Expansion: An efficient method for calculating gas-liquid equilibria in atmospheric aerosol particles:
}

\section{Inorganic compounds}

David Topping, ${ }^{1}$ Douglas Lowe, ${ }^{2}$ and Gordon McFiggans ${ }^{2}$

Received 10 March 2008; revised 10 November 2008; accepted 13 November 2008; published 18 February 2009.

[1] Parameterizations for calculating the equilibrium vapor pressure of the semivolatile inorganic gases, $\mathrm{HNO}_{3}, \mathrm{HCl}$, and $\mathrm{NH}_{3}$, above an aqueous aerosol are presented. The hybrid Partial Derivative Fitted Taylor Expansion (PD-FiTE) approach uses optimized model parameters describing the interaction between different inorganic ions, resulting in comparable computational performance with existing reduced methods while remaining accurate. Comparisons with the most accurate inorganic activity coefficient model available indicate that PD-FiTE performs very well over the parameterization space of the system $\mathrm{H}^{+}-\mathrm{NH}_{4}^{+}-\mathrm{Na}^{+}-\mathrm{SO}_{4}^{2-}-\mathrm{HSO}_{4}^{-}-\mathrm{NO}_{3}^{-}-\mathrm{Cl}^{-}$at $298.15 \mathrm{~K}$. The linear additive framework allows the inclusion of further species. However, including the ability to describe the interaction between inorganic and organic components will be presented in a future publication. Coupling PD-FiTE to a coupled box model of gaseous chemistry and aerosol microphysics in a test case investigating marine aerosol passing through a polluted environment demonstrates its robustness and ability to capture fine details of important phenomena such as the outgassing of $\mathrm{HCl}$ in response to $\mathrm{HNO}_{3}$ uptake by sea-salt particles.

Citation: Topping, D., D. Lowe, and G. McFiggans (2009), Partial Derivative Fitted Taylor Expansion: An efficient method for calculating gas-liquid equilibria in atmospheric aerosol particles: 1. Inorganic compounds, J. Geophys. Res., 114, D04304, doi:10.1029/2008JD010099.

\section{Introduction}

[2] Gas to particle mass transfer of semivolatile components, driven by a difference in equilibrium and actual partial pressures, is an important factor in determining the evolving chemical composition of aerosol particles and is necessary for predicting their loading and composition. This in turn has an impact on, for example, the potential of particles to form cloud droplets and resulting role in climate change [Solomon et al., 2007]. While capturing this behavior in large-scale models is essential, design of an appropriate framework required for process parameterization is challenging. Three dimensional chemical and aerosol transport models demand reduced computational expense, resulting in a trade-off between accuracy and efficiency. In this trade-off, activity coefficient calculations within the description of aerosol thermodynamics are routinely reduced. The following analysis demonstrates that parameterizations used to represent detailed processes can retain a high level of accuracy while also remaining efficient. The approach presented here builds on previously reported work, with an aim to derive param-

\footnotetext{
${ }^{1}$ National Centre for Atmospheric Science, School of Earth, Atmospheric and Environmental Science, University of Manchester, Manchester, UK.

${ }^{2}$ School of Earth, Atmospheric and Environmental Science, University of Manchester, Manchester, UK.

Copyright 2009 by the American Geophysical Union. 0148-0227/09/2008JD010099\$09.00
}

eters for an accurate and computationally efficient framework through coupling with a complex thermodynamic model. Maintaining reduced numerical complexity is important as it will be necessary to further include an as yet unspecified number of condensing organic species, thus increasing the computational burden of any existing framework. The focus in this study is on developing parameterizations used for calculating the equilibrium vapor pressure of key semivolatile inorganic species above an aqueous aerosol, namely $\mathrm{HNO}_{3}, \mathrm{HCl}$ and $\mathrm{NH}_{3}$. Since the vapor pressure of $\mathrm{H}_{2} \mathrm{SO}_{4}$ is so low [Marti et al., 1997], it is justified to assume direct condensation to the condensed phase. A broad objective of this study is to provide a generic reduced thermodynamic framework applicable across a wide range of compositions without describing specific areas of applicability. Since it has been contended that the stable condensed phase in atmospheric multicomponent aerosol is liquid [Marcolli et al., 2004] and the model framework has been designed with the ability to consider multicomponent inorganic-organic particles, the analysis reported here is restricted to deliquesced aqueous particles. Consideration of solid precipitation is straightforward and is briefly discussed. The inclusion of organic compounds into the framework will be reported in a separate publication. The current manuscript is concerned only with validation of the approach for the $\mathrm{H}^{+}-\mathrm{NH}_{4}^{+}-\mathrm{Na}^{+}-$ $\mathrm{SO}_{4}^{2-}-\mathrm{HSO}_{4}^{-}-\mathrm{NO}_{3}^{-}-\mathrm{Cl}^{-}$system. The parameterization is then incorporated into a coupled model of gaseous photochemistry and aerosol microphysics dynamically simulating aerosol 
composition and demonstrating model robustness of our model and also demonstrate the implications of its use.

\section{Model Reduction Philosophy}

[3] The focus of the current work is to create a computationally efficient and accurate parameterization for largescale models. The simplified thermodynamic scheme should satisfy a number of criteria. Most importantly, owing to the heavy computational burden provided by large-scale models, the parameterization must have a significantly reduced level of numerical complexity compared to more explicit frameworks. Second, the concentration range of components may cover several orders of magnitude and a model must provide a physically meaningful solution, across such concentration ranges. Finally, the model framework should be sufficiently flexible to allow incorporation of new data. The chosen approach is as follows. The contributions to $y$ by each of $N$ components $i$ could be expressed most simply by the following "additive" expression

$$
y=\sum_{i}^{N} x_{i} c_{i}
$$

where $x_{i}$ is a representation of the amount of species " $i$ " and $c_{i}$ a variable which defines the contribution of species " $i$ " to the value of $y$. The approach used here, described and justified in section 4.2, allows the form of equation (1) to be adopted by fitting the relationship to a thermodynamic model. This derivation of "optimized" first-order interaction parameters avoids the use of higher-order terms to account for binary "interactions" between components. The following section defines the relationships to be parameterized.

\section{Thermodynamic Model Reduction}

[4] The equilibrium pressure above an aerosol particle is determined by the nature of the semivolatile gas and the solution with which it is equilibrating. The chemical equilibrium between an inorganic acid MX, which dissociates into the ions $\mathrm{M}^{+}$and $\mathrm{X}^{-}$in solution, can be expressed using the following relationship

$$
P_{M X}=\frac{\left(v_{M} m_{M}\right)\left(v_{X} m_{X}\right) \gamma_{M X}^{V}}{K_{M X}}
$$

where $P_{M X}$ is the equilibrium vapor pressure above the solution (atm), $m_{M}$ is the molality of the ion $\mathrm{M}^{+}\left(\mathrm{mol} \mathrm{kg}^{1}\right)$, $m_{X}$ the molality of the ion $\mathrm{M}\left(\mathrm{mol} \mathrm{kg}{ }^{1}\right), \gamma_{M X}$ is the mean binary activity coefficient of the specie MX (molality scale), $v_{M}$ and $v_{X}$ the number of moles of cation $\mathrm{M}$ and $\mathrm{X}$ in the electrolyte MX, $v_{M X}=v_{M}+v_{X}$ and $K_{M X}$ is the Henry's law constant for the species in question $\left(\mathrm{mol}^{2} \mathrm{~kg}^{2} \mathrm{~atm}^{1}\right)$. For $\mathrm{HNO}_{3}$ and $\mathrm{HCl}$, equation (2) gives

$$
\begin{gathered}
P_{\mathrm{HNO}_{3}}=\frac{m_{\mathrm{H}^{+}} m_{\mathrm{NO}_{3}^{-}} \gamma_{\mathrm{HNO}_{3}}^{2}}{K_{\mathrm{HNO}_{3}}} \\
P_{\mathrm{HCl}}=\frac{m_{\mathrm{H}^{+}} m_{\mathrm{Cl}} \gamma_{\mathrm{HCl}}^{2}}{K_{\mathrm{HCl}}}
\end{gathered}
$$

Table 1. Henry's Law-Dissociation Constants Required for Activity Coefficient Calculations

\begin{tabular}{llll}
\hline Constant $^{\mathrm{a}}$ & \multicolumn{1}{c}{$K\left(T_{0}\right)$} & \multicolumn{1}{c}{$-\Delta H / R$} & \multicolumn{1}{c}{ Source $^{\mathrm{b}}$} \\
\hline$K_{\mathrm{HNO} 3}$ & $2.6 \times 10^{6}$ & $\mathrm{~mol}^{2} \mathrm{~kg}^{-2} \mathrm{~atm}^{-2}$ & $8700 \mathrm{CH}$ \\
$K_{\mathrm{HCl}}$ & $2.0 \times 10^{6}$ & $\mathrm{~mol}^{2} \mathrm{~kg}^{-2} \mathrm{~atm}^{-2}$ & $9000 \mathrm{WA}$ \\
$K_{\mathrm{NH} 4}$ & $1.7 \times 10^{5}$ & $\mathrm{~mol} \mathrm{~kg}^{-1}$ & $-4325 \mathrm{CH}$ \\
$K_{\mathrm{HCl}}$ & $5.8 \times 10^{1}$ & $\mathrm{~mol} \mathrm{~kg}^{-1} \mathrm{~atm}^{-1}$ & $4085 \mathrm{CH}$ \\
$K_{\mathrm{W}}$ & $1.0 \times 10^{-14}$ & $\mathrm{~mol}^{2} \mathrm{~kg}^{-2}$ & $-6716 \mathrm{CH}$ \\
$K_{\mathrm{HSO} 4}$ & $1.2 \times 10^{-3}$ & $\mathrm{~mol} \mathrm{~kg}^{-1}$ & $1120 \mathrm{WE}$ \\
\hline${ }^{\mathrm{a}}$ The temperature dependence is $K=K\left(T_{0}\right) \times \exp \left(-\Delta H / R\left(1 / T-1 / T_{0}\right)\right)$ \\
$T_{0}=298.15 \mathrm{~K}$. \\
${ }^{\mathrm{b}}$ Source: CH, Chameides [1984]; WA, Wagman et al. [1982]; WE, Weast \\
[1980].
\end{tabular}

The equilibrium vapor pressure of ammonia above a solution is more complicated and can be expressed as [Zaveri et al., 2005]

$$
P_{N H_{3}}=\left(\frac{m_{N H_{4}^{+}}}{m_{H^{+}}}\right)\left(\frac{\gamma_{N H_{4}^{+}}}{\gamma_{H^{+}}}\right)\left(\frac{K_{w}}{K_{N H_{4}} K_{H}}\right)
$$

where $K_{w}$ is the dissociation constant of water, $K_{\mathrm{NH} 4}$ the equilibrium constant of aqueous $\mathrm{NH}_{3}$ and $K_{H}$ the Henry's law constant of $\mathrm{NH}_{3}$. It is clear from expressions (3), (4) and (5) that there are three sets of variables to consider when calculating the equilibrium vapor pressure above a solution.

[5] 1. Henry's law-dissociation constants: These values are tabulated (Table 1).

[6] 2. The concentration of the appropriate ions: this requires calculation of the water associated with the particle and also the degree of dissociation of the bisulfate ion where appropriate due to its impact on the concentration of $\mathrm{H}^{+}$ (discussed in more detail in section 4.3). In order to deal with this it is necessary to account for solution thermodynamics implicit in the activity coefficient calculations.

[7] 3. Mean binary activity coefficients: activity coefficients are complex functions of the solution composition. Calculating activity coefficients is complicated, the multiple approaches discussed extensively in the literature [see Clegg and Seinfeld, 2006 and references therein]. Parameterization of activity coefficients provides the main focus of this work largely because reducing the numerical complexity while retaining a good level of accuracy is very challenging.

[8] The main focus of this study centers on building a parameterization of activity coefficients, whereas the water content is calculated using the widely used ZSR mixing rule, details of which can be found elsewhere [Stokes and Robinson, 1966].

\section{Efficiently Coupled Activity Coefficient Parameterization}

[9] Activity coefficient models are parameterizations of complicated thermodynamic behavior. The mean binary activity coefficient of an electrolyte $\mathrm{MX}, \gamma_{M X}$, is related to the activity coefficients of the individual ions by

$$
\gamma_{M X}=\left(\gamma_{M}^{v M} \cdot \gamma_{X}^{v X}\right)^{1 / v M X}
$$

where $\gamma_{M}$ and $\gamma_{X}$ are the activity coefficients of ions $\mathrm{M}$ and $\mathrm{X}$, $v_{M}$ and $v_{X}$ the number of moles of cation $\mathrm{M}$ and $\mathrm{X}$ in the electrolyte $\mathrm{MX}$ and $v_{M X}=v_{M}+v_{X}$. Calculating the activity 
coefficients of individual ions must be done theoretically as ions cannot be unpaired in solution. For inorganic systems, the Pitzer-Simonson-Clegg models (PSC) [Clegg et al., 1998a, 1998b] are regarded as the most accurate and robust inorganic activity coefficient model available for atmospheric purposes. However, these models remain too slow to be used in three-dimensional atmospheric chemistry models [Wexler and Clegg, 2002]. Capturing the correct limiting behavior using a simple additive framework for individual ions is difficult because one cannot calculate the activity coefficients of individual ions in a solution with no other ionic species. Hence in order to use relationship (1) an alternative representation of activity coefficients is required. The focus here is to calculate mean binary activity coefficients directly. However, we will demonstrate that by combining an empirical observation, based around the behavior of mean binary activity coefficients, and a numerical framework constrained by a complex thermodynamic model, we can use individual ions within an additive expression for $\gamma_{M X}$. In this way we do not rely on schemes for pairing up the individual ions in commonly used sulfate-"poor" and sulfate-"rich" domains. Empirical mixing rules are available [Bromley, 1973; Kusik and Meissner, 1978]. These schemes are much faster than the PSC models, are used extensively in atmospheric studies and have been shown to predict activity coefficients over a range of molalities fairly well [Nenes et al., 1998]. However, their applicability for saturated and supersaturated multicomponent solutions is limited by maximum ionic strengths up to which the mean binary activity coefficient parameterizations are valid. Also, their use usually entails expensive, repeated evaluations of the binary activity coefficients as the ionic strength changes in an iterative numerical solution for gas-liquid/solid partitioning. Metzger et al. [2002a, 2002b] formulated empirical equations for the activity coefficients of solutes as a function of relative humidity. However, Metzger et al. [2002a, 2002b] note how these equations break down for a sulfuric acid solution. As stated by Zaveri et al. [2005], since this scheme simply assumes that the multicomponent activity coefficient of each electrolyte is equal to its mean binary activity coefficient (possibly reasonable for dilute solutions when $\mathrm{RH}>80 \%$ ), it generally tends to break down for concentrated solutions. More recently, Zaveri et al. [2005] developed the multicomponent Taylor expansion method (MTEM), based on the series expansion rule used for dilute alloy solutions and extended this to aqueous electrolyte solutions at any concentration. The basis of the use of a Taylor Series expansion within MTEM is that variation of $\ln \gamma_{M X}$ with ionic mole fractions appears to be almost linear over the entire $\mathrm{RH}$ range. Thus the choice of concentration scale is based on the empirical behavior of the given multicomponent system rather than on ion solution thermodynamic theory [Zaveri et al., 2005]. In this study we use the same empirical observation and combine the linear Taylor Series expansion with an accurate thermodynamic equilibrium model (ADDEM [Topping et al., 2005a, 2005b] in an approach similar to those used in deriving complex semiempirical activity coefficient models such as Pitzer's method and the PSC model. Using a complex thermodynamic model to derive the terms $c_{i}$ in equation (1) (corresponding to $\frac{\partial \phi_{A}}{\partial \varsigma_{E}}$ in the work of Zaveri et al. [2005] (their equation (4)) with the above framework it is shown that that by finding the "optimum" parameters necessary for calculating $\gamma_{M X}$, it is possible to retain a high level of accuracy while reducing numerical complexity. A reduction of numerical complexity is crucial as one may wish to include any number of organic compounds in the future. The ethos used in this approach is potentially capable of incorporating complex mixed inorganicorganic thermodynamic schemes within the reduced format, explicitly accounting for the component interactions as data become available. However, the caveats and applicability of such extensions will be thoroughly reviewed in a future publication. Briefly, attempts have been made to formulate a coupled thermodynamic approach for atmospheric purposes [e.g., Ming and Russell, 2002; Clegg et al., 2001]. There remain significant difficulties with such schemes, mainly associated with a lack of experimental data from which interaction parameters can be derived. Because of this, various thermodynamic models use a flexible approach, using separate models for treating the inorganic and organic fractions. The approach presented here can incorporate individual treatment of each fraction individually, but can also exploit data from mixed inorganic-organic systems without the need to increase the numerical complexity of relationship (1). This is due to the method of finding "optimum" interaction parameters akin to semiempirical models and is discussed in more detail in the following section.

\subsection{Taylor Series Expansion}

[10] Here it is described how the current approach develops previous parameterizations by using a semiempirical approach and a thermodynamic equilibrium model. As mentioned above, it has been found empirically that $\ln \gamma_{M X}$ is almost linear over the entire $\mathrm{RH}$ range when using ionic mole fractions. Expressing $\ln \gamma_{A}$ as a function of $\mathrm{RH}$, thus water activity $a_{w}$, a Taylor Series expansion (neglecting curvature and temperature variation) gives

$$
\ln \gamma_{A}\left(x_{B}, x_{C}, x_{D}, \ldots R H\right)=\ln \gamma_{A}^{o}(R H)+\sum_{B \neq A}^{N}\left(\frac{\partial \ln \gamma_{A}}{\partial x_{B}}\right)(R H) x_{B}
$$

where $\ln \gamma_{A}^{o}(\mathrm{RH})$ is the value of $\ln \gamma_{A}$ at a given RH with no other solutes present, thus its value in a binary solution with only $\mathrm{H}_{2} \mathrm{O}$ and " $\mathrm{A}$ ". The variables $x_{B}, x_{C}, x_{D}$ take on values of ionic mole fractions defined by

$$
x_{A}=\frac{\nu_{A} N_{A}}{\sum_{E} \nu_{E} N_{E}}
$$

where $\nu_{A}$ is the stoichiometric coefficient for component " $\mathrm{A}$ " and $N_{A}$ the number of moles of solute "A". While both approaches rely on the same empirical observation, from this point onward, MTEM and the technique used here diverge. The method of calculation of partial derivatives in (7) is a major difference between this work and that of Zaveri et al. [2005]. Also, the composition space to which both models have been fit differ as will be discussed shortly. Briefly, while Zaveri et al. [2005] choose specific concentrations of, for example, $\mathrm{HNO}_{3}$, in this instance we use the entire composition space of $\mathrm{H}^{+}-\mathrm{NH}_{4}^{+}-\mathrm{Na}^{+}-\mathrm{SO}_{4}^{2-}-\mathrm{HSO}_{4}^{-}-\mathrm{NO}_{3}^{-}-\mathrm{Cl}^{-}$ with varying ratios of condensing gas to other aqueous solutes as discussed in section 4.2. We can tailor Partial 
Table 2. Electrolyte Formation According to the Sulfate Ratio Xt (See Text for Description) for Both MTEM and PD-FiTE

\begin{tabular}{|c|c|c|c|c|c|c|c|c|c|c|c|}
\hline \multirow[b]{3}{*}{ Electrolyte } & \multicolumn{4}{|c|}{ MTEM } & \multicolumn{4}{|c|}{ PD-FiTE } & \multirow{2}{*}{\multicolumn{2}{|c|}{ Interacting Ions }} & \multirow[b]{3}{*}{$v_{E}^{\complement}$} \\
\hline & \multicolumn{4}{|c|}{ Sulfate Ratio Regime } & \multicolumn{4}{|c|}{ Sulfate Ratio Regime } & & & \\
\hline & $0 \leq \mathrm{Xt}<1$ & $1 \leq \mathrm{Xt}<1.5$ & $1.5 \leq \mathrm{Xt}<2$ & $X t \geq 2$ & $0 \leq \mathrm{Xt}<1$ & $1 \leq \mathrm{Xt}<1.5$ & $1.5 \leq \mathrm{Xt}<2$ & $\mathrm{Xt} \geq 2$ & Cations & Anions & \\
\hline$\left(\mathrm{NH}_{4}\right)_{2} \mathrm{SO}_{4}$ & & & & $\mathrm{a}$ & $\mathrm{a}$ & $\mathrm{a}$ & $\mathrm{a}$ & $\mathrm{a}$ & $\mathrm{NH}_{4}^{+}$ & $\mathrm{SO}_{4}^{2-}$ & $\overline{6}$ \\
\hline $\mathrm{NH}_{4} \mathrm{NO}_{3}$ & & & & $\mathrm{a}$ & a & a & a & $\mathrm{a}$ & $\mathrm{NH}_{4}^{+}$ & $\mathrm{NO}_{3}^{-}$ & 4 \\
\hline $\mathrm{NH}_{4} \mathrm{Cl}$ & & & & a & $\mathrm{a}$ & $\mathrm{a}$ & $\mathrm{a}$ & $\mathrm{a}$ & $\mathrm{NH}_{4}^{+}$ & $\mathrm{Cl}^{-}$ & 4 \\
\hline $\mathrm{Na}_{2} \mathrm{SO}_{4}$ & & & & a & $\mathrm{a}$ & a & $\mathrm{a}$ & $\mathrm{a}$ & $\mathrm{Na}^{+}$ & $\mathrm{SO}_{4}^{2-}$ & 6 \\
\hline $\mathrm{NaNO}_{3}$ & & & & $\mathrm{a}$ & a & a & $\mathrm{a}$ & $\mathrm{a}$ & $\mathrm{Na}^{+}$ & $\mathrm{NO}_{3}^{-}$ & 4 \\
\hline $\mathrm{NaCl}$ & & & & a & $\mathrm{a}$ & a & a & $\mathrm{a}$ & $\mathrm{Na}^{+}$ & $\mathrm{Cl}^{-}$ & 4 \\
\hline $\mathrm{HNO}_{3}$ & & & & a & $\mathrm{a}$ & a & $\mathrm{a}$ & $\mathrm{a}$ & $\mathrm{H}^{+}$ & $\mathrm{NO}_{3}^{-}$ & 4 \\
\hline $\mathrm{HCl}$ & & & & a & a & $\mathrm{a}$ & a & a & $\mathrm{H}^{+}$ & $\mathrm{Cl}^{-}$ & 4 \\
\hline $\mathrm{H}_{2} \mathrm{SO}_{4}$ & $\mathrm{a}$ & & & & a & a & a & a & $\mathrm{H}^{+}$ & $\mathrm{SO}_{4}^{2-}$ & 6 \\
\hline $\mathrm{NH}_{4} \mathrm{HSO}_{4}$ & $\mathrm{a}$ & a & & & & & & & & & \\
\hline $\mathrm{NaHSO}_{4}$ & a & a & & & & & & & & & \\
\hline$\left(\mathrm{NH}_{4}\right)_{3} \mathrm{H}\left(\mathrm{SO}_{4}\right)_{2}$ & & $\begin{array}{l}\mathrm{a} \\
\mathrm{a}\end{array}$ & $\begin{array}{c}\mathrm{a} \\
\mathrm{a}\end{array}$ & & & & & & & & \\
\hline $\mathrm{Na}_{3} \mathrm{H}\left(\mathrm{SO}_{4}\right)_{2}$ & & a & a & & & & & & & & \\
\hline $\begin{array}{l}\left(\mathrm{NH}_{4}\right)_{2} \mathrm{SO}_{4} \\
\mathrm{Na}_{2} \mathrm{SO}_{4}\end{array}$ & & & a & & & & & & & & \\
\hline
\end{tabular}

${ }^{a}$ This highlights which salts (listed on the left) are used according to the different regimes defined by the column headers. I.e., if the salt has an "a" listed then it is used for the regime defined by the column header under which the "a" occurs.

Derivative Fitted Taylor Expansion (PD-FiTE) to more specific regimes as discussed in more detail in section 6.3 , but present optimized parameters derived from the entire composition space here. Returning to the discussion of numerical frameworks, in MTEM Zaveri et al. [2005] evaluated the partial derivatives using finite differences. Thus

$$
\ln \gamma_{A}(R H)=\sum_{B=1}^{N} x_{B} \ln \gamma_{A-B}^{0}(R H)
$$

where, due to the assumption of finite differences, $\ln \gamma_{A-B}^{0}(\mathrm{RH})$ is the mean activity coefficient of $\mathrm{A}$ in a ternary solution of A-B- $\mathrm{H}_{2} \mathrm{O}$ as the amount of electrolyte A approaches zero, tabulated as fifth-order polynomials for all solutes considered. We however do not make the simplifying assumption leading to a finite difference approach and retain the primitive (i.e., not approximate) form of the Taylor series expansion (equation (7)) and explicitly derive partial derivatives using the ADDEM [Topping et al., 2005a, 2005b] thermodynamic model, the specific details and sensitivity given in the following section. This approach is referred to hereafter as the Partial Derivative Fitted Taylor Series Expansion (PD-FiTE). It relies on the same procedure used to derive parameters in semiempirical thermodynamic frameworks; fitting equation (7) to a full treatment of nonideality. To do this, the solutes present in solution must first be defined using an ion pairing method. At this point the numerical basis of PD-FiTE and MTEM differ completely as we can reexpress equation (7) in terms of the binary combinations of the inorganic ions. Specifically, we can execute some numerical cancellations because we use the same ion pairing method in defining the complete solution space to fit parameters within equation (7) and also the application of equation (7) to any system. In PD-FiTE, the mixing scheme of Reilly and Wood [1969] is used to calculate the amount of solutes present for solute activity coefficients in Table 2, and thus define the composition space to which model parameters have been fitted.

$$
N_{M X}=2 N_{m} N_{X} \frac{\left(Z_{m} Z_{X} /\left(V_{M(X)} V_{X(M)}\right)\right)^{1 / 2}}{\left(\sum_{c} N_{c} Z_{c}+\sum_{a} N_{a} Z_{a}\right)}
$$

where $N_{M}$ is the number of moles of components $\mathrm{M}, \mathrm{Z}_{\mathrm{M}}$ the charge on component $\mathrm{M}, \mathrm{V}_{\mathrm{M}(\mathrm{X})}$ the stoichiometric coefficient of component $\mathrm{M}$ in the salt $\mathrm{N}_{\mathrm{MX}}$. This has been used in various atmospheric models [Clegg et al., 2001; Topping et al., 2005a] and uses the total concentrations of $\mathrm{H}^{+}$and $\mathrm{SO}_{4}^{2-}$, prior to consideration of $\mathrm{HSO}_{4}^{-}$formation. While this mixing rule has potential difficulties dealing with salts such as $\mathrm{NH}_{4} \mathrm{HSO}_{4}$, as stated previously, the predefined fully neutralized solutes for calculating activity coefficients and any partial dissociation effects on the activities are implicitly accounted for in the interaction parameters by fitting to ADDEM. Using equation (10) to calculate ionic mole fractions in equation (8), we are left with the following expression.

$$
x_{A}=\frac{\nu_{A}\left(2 N_{m} N_{X}\left(Z_{m} Z_{X} /\left(V_{M(X)} V_{X(M)}\right)\right)^{1 / 2}\right)}{\sum_{E} \nu_{E}\left(2 N_{E, m} N_{E, X}\left(Z_{E, m} Z_{E, X} /\left(V_{E, M(X)} V_{E, X(M)}\right)\right)^{1 / 2}\right)}
$$

[11] Substituting (11) back into (7) gives the following

$$
\begin{aligned}
\ln \gamma_{A}\left(x_{B}, x_{C}, x_{D}, \ldots R H\right) \\
=\ln \gamma_{A}^{o}(R H)+\frac{1}{\Omega} \sum_{B \neq A}^{N}\left(\frac{\partial \ln \gamma_{A}}{\partial x_{B}}\right)(R H) \\
\quad \cdot \nu_{B}\left(2 N_{B, M} N_{B, X}\left(Z_{B, M} Z_{B, X} /\left(V_{B, M(X)} V_{B, X(M)}\right)\right)^{1 / 2}\right)
\end{aligned}
$$

where $N_{B, M}$ is the number of moles of components $\mathrm{M}$ in electrolyte $\mathrm{B}, \mathrm{Z}_{\mathrm{B}, \mathrm{M}}$ the charge on component $\mathrm{M}, \mathrm{V}_{\mathrm{B}, \mathrm{M}(\mathrm{X})}$ the stoichiometric coefficient of component $\mathrm{M}$ in the electrolyte B. Similarly, $\Omega$ is given by

$$
\Omega=\sum_{E} \nu_{E}\left(2 N_{E, m} N_{E, X}\left(Z_{E, m} Z_{E, X} /\left(V_{E, M(X)} V_{E, X(M)}\right)\right)^{1 / 2}\right)
$$

[12] For the 9 predefined solutes, thus binary ion pairs, used within this study, equation (13) reduces to

$$
\Omega=\sum_{E} \nu_{E}^{\subset} N_{E, M} N_{E, X}
$$


[13] The values of $\nu_{E}^{\subset}$ for each of the predefined solutes, thus ion pairs, are given in Table 2.

[14] Reexpressing (12) using individual ions, along with the stoichiometric and charge data for the 9 predefined solutes listed in Table 2, we are left with the following expression.

$$
\begin{aligned}
& \ln \gamma_{A}\left(N_{H}, N_{N H 4}, \ldots R H\right) \\
& =\ln \gamma_{A}^{o}(R H)+\frac{1}{\Omega} \sum_{B \neq A}^{N}\left(\sum_{M} \sum_{X}\left(\frac{\partial \ln \gamma_{A}}{\partial\left(N_{B, M}, N_{B, X}\right)}\right)^{c}\right. \\
& \left.\cdot(R H) N_{B, M} N_{B, X}\right)
\end{aligned}
$$

where the polynomials $\left(\frac{\partial \ln \gamma_{A}}{\partial\left(N_{B, M}, N_{B, X}\right)}\right) \subset$ are listed in Tables 3 and 4 and discussed in section 4.2. Hence we arrive at an expression for $\ln \gamma_{A}$ in terms of binary combinations of all ions within the composition space $\mathrm{H}^{+}-\mathrm{NH}_{4}^{+}-\mathrm{Na}^{+}-\mathrm{SO}_{4}^{2-}$ $\mathrm{HSO}_{4}^{-}-\mathrm{NO}_{3}^{-}-\mathrm{Cl}^{-}$. For example, to calculate $\gamma_{\mathrm{HNO} 3}$ in the composition space $\mathrm{H}^{+}-\mathrm{NH}_{4}-\mathrm{SO}_{4}^{2-}-\mathrm{NO}_{3}^{-}$, the following expression is used.

$$
\begin{aligned}
\ln \gamma_{\mathrm{HNO}_{3}}(R H)= & \ln \gamma_{\mathrm{HNO}_{3}}^{o}(R H)+\frac{1}{\Omega}\left(\left(\frac{\partial \ln \gamma_{\mathrm{HNO}_{3}}}{\partial\left(N_{\mathrm{H}} N_{\mathrm{SO}_{4}}\right)}\right)\right. \\
& \cdot(R H) N_{H} N_{\mathrm{SO}_{4}}+\left(\frac{\partial \ln \gamma_{\mathrm{HNO}_{3}}}{\partial\left(N_{\left.\mathrm{NH}_{4} N_{S O_{4}}\right)}\right)}\right. \\
& \cdot(R H) N_{\mathrm{NH}_{4} N_{S O_{4}}} \\
& \left.+\left(\frac{\partial \ln \gamma_{\mathrm{HNO}_{3}}}{\partial\left(N_{\mathrm{NH}_{4}} N_{\mathrm{NO}_{3}}\right)}\right)(R H) N_{\mathrm{NH}_{4} N_{N O_{3}}}\right)
\end{aligned}
$$

where

$$
\Omega=\left(6 * N_{H} * N_{S_{4}}+6 * N_{N_{4}} * N_{S O_{4}}+4 * N_{N_{4}} * N_{N_{3}}\right) .
$$

[15] The solution composition and hence contributions to activity coefficients are fixed using the same electrolytes listed in Table 2, avoiding the need to define sulfate-"rich" and sulfate-"poor" domains. This is possible because the ADDEM thermodynamic equilibrium is used to derive the optimum partial derivatives within equation (7) across the "entire" composition space, thus taking into account any partial dissociation effects on $\ln \gamma_{A}$. The approach by Zaveri et al. [2005] was to use $\ln \gamma_{A-B}^{0}$ for specific solutes depends on whether one is in a sulfate-"poor" or sulfate-"rich" domain. Thus the behavior of $\ln \gamma_{A}$ is combined with a partitioning scheme for determining the unique electrolyte composition. This is an extremely flexible approach and particularly beneficial for future expansion. In the sulfate"poor" domain, $\mathrm{S}(\mathrm{VI})$ is completely neutralized exists as $\mathrm{SO}_{4}^{2-}$ since $\mathrm{HSO}_{4}^{-}$is completely dissociated. In the sulfate"rich" domain S(VI) isn't completely neutralized, allowing partial dissociation of the bisulfate ion $\mathrm{HSO}_{4}^{-}$. The sulfate"rich" and -"poor" domains are determined by using the sulfate ratio $X_{T}$. This is defined as

$$
X_{T}=\frac{N_{N H_{4}^{+}}+N_{N a^{+}}+2 N_{\mathrm{Ca}^{2+}}}{N_{S U L F}}
$$

where $N_{S U L F}=N_{S O 4}+N_{H S O 4}$. In the sulfate-poor domain $X_{T} \geq 2$, whereas in the sulfate-rich domain $X_{T}<2$. The solutes which are manually allowed to form in MTEM are given in Table 2 as taken from the work of Zaveri et al. [2005].

[16] Thus the calculations for both $\mathrm{HNO}_{3}$ and $\mathrm{HCl}$ in PDFiTE remain the same for all sulfate regimes, whereas the same calculations in MTEM change dependent on which sulfate regime you are in. When deriving the partial derivatives we explicitly fit the PD-FiTE framework (equation (15)), and the concentration of 9 predefined solutes (thus individual ions), to the thermodynamic model ADDEM. The binary activity coefficients of $\mathrm{HNO}_{3}$ and $\mathrm{HCl}$ in PD-FiTE were taken from the PSC activity model and are expressed as functions of $\mathrm{RH}$ in the form of

$$
\ln \gamma^{o}(R H)=B o+B 1 * R H+B 2 * R H^{2}+B 3 * R H^{3}+\ldots
$$

where the parameters Bo, B1 etc are given in Table 5. Note that all of the functions are given as cubic expressions apart from the expression for $\ln \gamma_{H N O 3}^{o}(\mathrm{RH})$ below $40 \% \mathrm{RH}$ whereby a fourth-order polynomial is required.

[17] Attention should be given to calculating the required activity coefficients for calculating the vapor pressure of ammonia above a solution as the formulation between MTEM and PD-FiTE is different. The partial pressure of $\mathrm{NH}_{3}$ is given as

$$
P_{N H_{3}}=\left(\frac{m_{N H_{4}^{+}}}{m_{H^{+}}}\right)\left(\frac{\gamma_{N H_{4}^{+}}}{\gamma_{H^{+}}}\right)\left(\frac{K_{w}}{K_{N H_{4}^{+}} K_{H}}\right)
$$

where $K_{w}\left(\mathrm{~mol}^{2} \mathrm{~kg}^{-2}\right)$ is the dissociation constant of water, $K_{\mathrm{NH} 4}\left(\mathrm{~mol} \mathrm{~kg}^{-1}\right)$ the dissociation constant of aqueous $\mathrm{NH}_{3}$ and $K_{H}$ the Henry's law constant of $\mathrm{NH}_{3}\left(\mathrm{~mol} \mathrm{~kg}^{-1} \mathrm{~atm}^{-1}\right)$. In MTEM the ratio of the individual ions is replaced by the following expression.

$$
\frac{\gamma_{N H_{4}^{+}}}{\gamma_{H^{+}}}=\frac{\gamma_{N H_{4}^{+}} \gamma_{H S O_{4}^{-}}}{\gamma_{H^{+}} \gamma_{H S O_{4}^{-}}}=\frac{\gamma_{N H_{4} H S O_{4}}^{2}}{\gamma_{H H S O_{4}}^{2}}
$$

requiring the evaluation of both $\gamma_{\mathrm{NH} 4 \mathrm{HSO} 4}^{2}$ and $\gamma_{\mathrm{HHSO} 4}^{2}$, which are given as fifth-order polynomials for a given RH. In PD-FiTE we retain the original form of the relationship (21) and fit the ratio of individual ion activity coefficients to the ADDEM thermodynamic model using the solutes (ion combinations) listed in Table 2. $\left(\frac{\gamma_{N H_{4}^{+}}}{\gamma_{H^{+}}}\right)$is evaluated using polynomials of varying order within the following relationship.

$$
\begin{aligned}
\ln \left(\frac{\gamma_{N H_{4}^{+}}}{\gamma_{H^{+}}}\right)(R H)= & \frac{1}{\Omega} \sum_{B=1}^{N} \sum_{M} \sum_{X} \\
& \cdot\left(\frac{\partial \ln \left({ }^{\gamma_{N H_{4}^{+}}} /\right.}{\partial\left(N_{B, M} N_{\gamma_{H}}\right)}\right) \\
& (R H) N_{B, M} N_{B, X}
\end{aligned}
$$

[18] Relationship (15) is thereby simplified (removing calculation of the activity coefficients for $\mathrm{NH}_{4} \mathrm{HSO}_{4}$ and $\mathrm{HHSO}_{4}$ in equation (21)). This is clear in the discussion of computational expense in section 6.3. The ability of this approach to reproduce $\left(\frac{\gamma_{N H 4}}{\gamma_{H}}\right)$ is discussed in section 6.1. For 
Table 3. Coefficients for Polynomial Fits Used in Calculating Partial Derivatives in Equation (15) in the $\mathrm{Text}_{\mathrm{for}} \mathrm{HNO}_{3}, \mathrm{HCl}$, and $\mathrm{NH}_{3}{ }^{\mathrm{a}}$

\begin{tabular}{|c|c|c|c|c|c|c|c|c|c|c|}
\hline \multirow{2}{*}{$\begin{array}{l}\text { Primary } \\
\text { Compound }\end{array}$} & \multicolumn{2}{|c|}{ Interacting Ions } & \multirow{2}{*}{$\begin{array}{l}\text { Interacting } \\
\text { Compound }\end{array}$} & \multirow[b]{2}{*}{ RH Range (\%) } & \multicolumn{6}{|c|}{ Polynomial Coefficients } \\
\hline & Cations & Anions & & & B0 & B1 & B2 & B3 & B4 & B5 \\
\hline \multirow[t]{9}{*}{$\mathrm{HNO}_{3}$} & $\mathrm{H}$ & $\mathrm{Cl}^{-}$ & $\mathrm{HCl}$ & $\begin{array}{l}10-99 \\
40-99\end{array}$ & 19.2728 & -86.552 & 180.564 & -177.428 & 64.204 & \\
\hline & $\mathrm{H}$ & $\mathrm{SO}_{4}^{2-}$ & $\mathrm{H}_{2} \mathrm{SO}_{4}$ & $10-99$ & 9.3948 & -26.808 & 35.7654 & -18.5094 & & \\
\hline & $\mathrm{NH}_{4}^{+}$ & $\mathrm{SO}_{4}^{2-}$ & $\begin{array}{l}\left(\mathrm{NH}_{4}\right)_{2} \mathrm{~S}- \\
\mathrm{O}_{4}\end{array}$ & $\begin{array}{l}40-99 \\
10-99\end{array}$ & -40.4136 & 108.798 & -170.346 & 100.926 & & \\
\hline & $\mathrm{NH}_{4}^{+}$ & $\mathrm{NO}_{3}^{-}$ & $\mathrm{NH}_{4} \mathrm{NO}_{3}$ & $10-99$ & -17.0372 & 59.232 & -86.312 & 44.04 & & \\
\hline & $\mathrm{NH}_{4}^{+}$ & $\mathrm{Cl}^{-}$ & $\mathrm{NH}_{4} \mathrm{Cl}$ & $\begin{array}{l}10-99 \\
40-99\end{array}$ & -0.22072 & -15.5168 & 20.3312 & -4.704 & & \\
\hline & $\mathrm{Na}^{+}$ & $\mathrm{SO}_{4}^{2-}$ & $\mathrm{Na}_{2} \mathrm{SO}_{4}$ & $\begin{array}{l}40-99 \\
10-99\end{array}$ & $\begin{array}{l}1.53 / 44 \\
33.6096\end{array}$ & $\begin{array}{l}-9.0436 \\
-170.766\end{array}$ & $\begin{array}{l}10.4876 \\
403.956\end{array}$ & -480.606 & 213.024 & \\
\hline & $\mathrm{Na}^{+}$ & $\mathrm{NO}_{3}^{-}$ & $\mathrm{NaNO}_{3}$ & $10-99$ & -5.8804 & 43.324 & -163.18 & 298.744 & -267.668 & 94.636 \\
\hline & & & & $40-99$ & 5.442 & -48.304 & 124.784 & -140.948 & 58.996 & \\
\hline & $\mathrm{Na}^{+}$ & $\mathrm{Cl}^{-}$ & $\mathrm{NaCl}$ & $\begin{array}{l}10-99 \\
40-99\end{array}$ & $\begin{array}{l}10.5104 \\
2.6684\end{array}$ & $\begin{array}{l}-58.344 \\
-3.0568\end{array}$ & $\begin{array}{l}133.588 \\
-4.4148\end{array}$ & $\begin{array}{l}-140.488 \\
4.7528\end{array}$ & 54.728 & \\
\hline \multirow[t]{12}{*}{$\mathrm{HCl}$} & $\mathrm{H}$ & $\mathrm{NO}_{3}^{-}$ & $\mathrm{HNO}_{3}$ & $10-99$ & 8.8772 & -51.832 & 110.488 & -106.028 & 38.5024 & \\
\hline & & & & $40-99$ & 2.22824 & -7.5308 & 5.2968 & & & \\
\hline & $\mathrm{H}$ & $\mathrm{SO}_{4}^{2-}$ & $\mathrm{H}_{2} \mathrm{SO}_{4}$ & $10-99$ & 1.51356 & 6.084 & -16.2792 & 8.6436 & & \\
\hline & & & & $40-99$ & 4.01478 & -5.95026 & 1.85958 & & & \\
\hline & $\mathrm{NH}_{4}^{+}$ & $\mathrm{SO}_{4}^{2-}$ & $\begin{array}{l}\left(\mathrm{NH}_{4}\right)_{2} \mathrm{~S}- \\
\mathrm{O}_{4}\end{array}$ & $10-99$ & -56.6028 & 167.358 & -244.068 & 132.426 & & \\
\hline & $\mathrm{NH}_{4}^{+}$ & $\mathrm{NO}_{3}^{-}$ & $\mathrm{NH}_{4} \mathrm{NO}_{3}$ & $10-99$ & -35.47 & 125.1 & -169.34 & 79.74 & & \\
\hline & $\mathrm{NH}_{4}^{+}$ & & $\mathrm{NH}_{4} \mathrm{Cl}$ & $10-99$ & -6.7296 & 12.7884 & -17.2728 & 11.2192 & & \\
\hline & $\mathrm{Na}^{+}$ & $\mathrm{SO}^{2-}$ & $\mathrm{Na}_{2} \mathrm{SO}$ & $\begin{array}{r}40-99 \\
10-99\end{array}$ & -4.2572 & -0.73048 & 4.9216 & & & \\
\hline & $\mathrm{Na}^{+}$ & $\mathrm{NO}_{3}^{-}$ & $\begin{array}{l}\mathrm{Na}_{2} \mathrm{SO}_{4} \\
\mathrm{NaNO}_{3}\end{array}$ & $\begin{array}{l}10-99 \\
10-99\end{array}$ & $\begin{array}{l}34.2042 \\
-9.71\end{array}$ & $\begin{array}{l}-160.362 \\
101.236\end{array}$ & $\begin{array}{l}380.646 \\
-392704\end{array}$ & -471.948 & $\begin{array}{l}216.624 \\
-63768\end{array}$ & 217884 \\
\hline & & & & $40-99$ & 10.7384 & -74.076 & 189.14 & -212.352 & 86.528 & 217.884 \\
\hline & $\mathrm{Na}^{+}$ & $\mathrm{Cl}^{-}$ & $\mathrm{NaCl}$ & $10-99$ & 1.40896 & -13.2656 & 38.508 & -48.316 & 21.6552 & \\
\hline & & & & $40-99$ & -1.9048 & 9.5336 & -17.3812 & 9.728 & & \\
\hline \multirow[t]{15}{*}{$\mathrm{NH}_{3}{ }^{\mathrm{b}}$} & $\mathrm{H}$ & $\mathrm{NO}_{3}^{-}$ & $\mathrm{HNO}_{3}$ & $10-99$ & -39.1996 & 84.264 & -99.276 & 54.108 & & \\
\hline & & & & $40-99$ & -24.6204 & 11.9268 & 12.3128 & & & \\
\hline & $\mathrm{H}$ & $\mathrm{Cl}^{-}$ & $\mathrm{HCl}$ & $\begin{array}{l}10-99 \\
40-99\end{array}$ & $\begin{array}{l}-41.968 \\
-289316\end{array}$ & $\begin{array}{l}92.352 \\
28.8656\end{array}$ & -95.812 & 45.496 & & \\
\hline & $\mathrm{H}$ & $\mathrm{SO}_{4}^{2-}$ & $\mathrm{H}_{2} \mathrm{SO}_{4}$ & $10-99$ & -72.978 & 165.162 & -177.51 & 85.332 & & \\
\hline & & & & $40-99$ & -49.3404 & 48.984 & & & & \\
\hline & $\mathrm{NH}_{4}^{+}$ & $\mathrm{SO}_{4}^{2-}$ & $\left(\mathrm{NH}_{4}\right)_{2} \mathrm{~S}-$ & $10-99$ & -15.213 & 79.782 & -193.326 & 262.77 & -133.71 & \\
\hline & & & $\mathrm{O}_{4}$ & & $40-99$ & 15.8754 & -108.132 & 218.106 & -125.502 & \\
\hline & $\mathrm{NH}_{4}$ & $\mathrm{NO}_{3}^{-}$ & $\mathrm{NH}_{4} \mathrm{NO}_{3}$ & $\begin{array}{l}10-99 \\
40-99\end{array}$ & $\begin{array}{l}-25.8256 \\
-31.4296\end{array}$ & $\begin{array}{l}12.772 \\
30.898\end{array}$ & 13.058 & & & \\
\hline & $\mathrm{NH}_{4}^{+}$ & $\mathrm{Cl}^{-}$ & $\mathrm{NH}_{4} \mathrm{Cl}$ & $10-99$ & -57.256 & 171.224 & -207.656 & 93.688 & & \\
\hline & $\mathrm{Na}^{+}$ & $\mathrm{SO}_{4}^{2-}$ & $\mathrm{Na}_{2} \mathrm{SO}_{4}$ & $\begin{array}{l}40-99 \\
10-99\end{array}$ & $\begin{array}{l}-24.7988 \\
-120.996\end{array}$ & $\begin{array}{l}24.1492 \\
449.508\end{array}$ & -912.36 & 983.46 & -399.294 & \\
\hline & & & & $40-99$ & -84.414 & 148.11 & -62.658 & & & \\
\hline & $\mathrm{Na}^{+}$ & $\mathrm{NO}_{3}^{-}$ & $\mathrm{NaNO}_{3}$ & $10-99$ & -55.616 & 119.364 & -126.84 & 63.084 & & \\
\hline & & & & $40-99$ & -39.7604 & 39.2344 & & & & \\
\hline & $\mathrm{Na}^{+}$ & $\mathrm{Cl}^{-}$ & $\mathrm{NaCl}$ & $10-99$ & -49.916 & 121.612 & -141.068 & 69.62 & & \\
\hline & & & & $40-99$ & -32.98 & 32.8972 & & & & \\
\hline
\end{tabular}

${ }^{\mathrm{a}}$ The primary compound $\left(\mathrm{HNO}_{3}, \mathrm{HCl}\right.$, or $\left.\mathrm{NH}_{3}\right)$ or compound for which activity coefficient data are required is given in the left hand column. The 'interacting' compound, represented by the combinations of ions displayed in the second column, is displayed in the third column. The range of RH for which the coefficients are valid is given in the third column. Values presented in italics represent coefficients for reduced order polynomials applicable within a defined RH regime (see text).

${ }^{\mathrm{b}}$ For condensing $\mathrm{NH}_{3}$, these polynomials are required for calculating the ratio of activity coefficients for the ions $\mathrm{H}^{+}$and $\mathrm{NH}_{4}^{+}$in solution (see text).

clarity, note that the polynomials used to calculate equation (22) are not constrained to sulfate-rich systems and are similarly applicable across sulfate-poor systems.

\subsection{Efficient Hybrid Mixing Rule-Explicit Thermodynamic Model Approach}

[19] This section describes the procedure used for deriving the optimized partial derivatives used in expression (15). The thermodynamic model ADDEM, using the PSC activity coefficient model, was used to derive a data set of activity coefficients covering all the permutations within the solution space $\mathrm{H}^{+}-\mathrm{NH}_{4}^{+}-\mathrm{Na}^{+}-\mathrm{SO}_{4}^{2-}-\mathrm{HSO}_{4}^{-}-\mathrm{NO}_{3}^{-}-\mathrm{Cl}^{-}$, across relative humidities from $10 \%$ to $99 \%$. Before a sensitivity analysis of the required resolution used to derive such parameters is given, the full range of possible composition combinations was represented by 8 two-dimensional composition subdo- mains with each apex representing a different solute from the 9 listed in Table 2 (Figure 1). These subdomains were represented by 11 incremental changes in the molar ratio of each solute moving across both the $x$ and $y$ axis (thus a total of 1089 data points). Since the semivolatile species $\mathrm{HNO}_{3}, \mathrm{HCl}$ and $\mathrm{NH}_{3}$ are of primary interest, the molar ratio of each condensing gas was then varied in relation to other aqueous solutes in each subdomain from 100:1, to $1: 100$ using different levels of granularity as discussed shortly. While this was carried out at $298.15 \mathrm{~K}$ (the inclusion of temperature dependence discussed in section 5), the relative humidity was then varied from 10 to $99 \%$ and the procedure repeated for each point. PD-FiTE was then fitted to the subsequent matrix of activity coefficients using a nonlinear Levenberg-Marquard least squares fitting algorithm in the Matlab software package (www.mathworks.com). As any least squares fitting routine is 
Table 4. Coefficients for Polynomial Fits Used in Calculating Partial Derivatives in Equation (27) in the $\mathrm{Text}_{\text {for }} \mathrm{HHSO}_{4}$ and $\mathrm{H}_{2} \mathrm{SO}_{4}{ }^{\mathrm{a}}$

\begin{tabular}{|c|c|c|c|c|c|c|c|c|c|c|c|c|}
\hline \multirow{2}{*}{$\begin{array}{c}\text { Primary } \\
\text { Compound }\end{array}$} & \multicolumn{2}{|c|}{ Interacting Ions } & \multirow{2}{*}{$\begin{array}{l}\text { Interacting } \\
\text { Compound }\end{array}$} & \multirow[b]{2}{*}{ RH Range (\%) } & \multicolumn{8}{|c|}{ Polynomial Coefficients } \\
\hline & Cations & Anions & & & B0 & $\mathrm{B} 1$ & B2 & B3 & B4 & B5 & B6 & B7 \\
\hline \multirow[t]{10}{*}{$\mathrm{H}_{2} \mathrm{SO}_{4}$} & $\mathrm{H}$ & $\mathrm{NO}_{3}^{-}$ & $\mathrm{HNO}_{3}$ & $10-99$ & 8.5472 & -50.16 & 137.44 & -216.596 & 186.708 & -65.528 & & \\
\hline & $\mathrm{H}$ & $\mathrm{Cl}^{-}$ & $\mathrm{HCl}$ & $10-99$ & 0.338508 & -23.206 & 98.672 & -188.96 & 171.96 & -57.636 & & \\
\hline & $\mathrm{NH}_{4}^{+}$ & $\mathrm{SO}_{4}^{2-}$ & $\left(\mathrm{NH}_{4}\right)_{2} \mathrm{SO}_{4}$ & $10-99$ & -48.3636 & 235.092 & -726.24 & 1263.42 & -1125 & 400.26 & & \\
\hline & $\mathrm{NH}_{4}^{+}$ & $\mathrm{NO}_{3}^{-}$ & $\mathrm{NH}_{4} \mathrm{NO}_{3}$ & $10-99$ & -27.8844 & 150.552 & -298.588 & 266.46 & -90.128 & & & \\
\hline & $\mathrm{NH}_{4}^{+}$ & $\mathrm{Cl}^{-}$ & $\mathrm{NH}_{4} \mathrm{Cl}$ & $10 \leq \mathrm{RH}<20$ & 2.30952 & -1.28356 & & & & & & \\
\hline & & & & $20 \leq \mathrm{RH}<90$ & 4.2192 & -3.7374 & -68.048 & 201.28 & -204.332 & 72.356 & & \\
\hline & & & & $90 \leq \mathrm{RH} \leq 99$ & 6.8008 & -6.2996 & & & & & & \\
\hline & $\mathrm{Na}$ & $\mathrm{SO}_{4}^{2-}$ & $\mathrm{Na}_{2} \mathrm{SO}_{4}$ & $10-99$ & 46.5336 & -179.244 & 369.042 & -416.502 & 179.058 & & & \\
\hline & $\mathrm{Na}$ & $\mathrm{NO}_{3}^{-}$ & $\mathrm{NaNO}_{3}$ & $10-99$ & -7.8256 & 148.968 & -714.44 & 1772.32 & -2418.72 & 1709.72 & -489.48 & \\
\hline & $\mathrm{Na}$ & $\mathrm{Cl}^{-}$ & $\mathrm{NaCl}$ & $10-99$ & 17.0704 & -88.496 & 290.608 & -519.96 & 462.44 & -161.152 & & \\
\hline \multirow{10}{*}{$\mathrm{HHSO}_{4}$} & $\mathrm{H}$ & $\mathrm{NO}_{3}^{-}$ & $\mathrm{HNO}_{3}$ & $10-99$ & -7.6016 & 25.836 & -49.924 & 48.772 & -16.8816 & & & \\
\hline & $\mathrm{H}$ & $\mathrm{Cl}^{-}$ & $\mathrm{HCl}$ & $10-99$ & 2.40192 & -26.198 & 175.068 & -600.28 & 1176.84 & -1346.36 & 838.16 & -219.38 \\
\hline & $\mathrm{NH}_{4}^{+}$ & $\mathrm{SO}_{4}^{2-}$ & $\left(\mathrm{NH}_{4}\right)_{2} \mathrm{SO}_{4}$ & $10-99$ & -49.9236 & 120.066 & -172.5 & 100.608 & & & & \\
\hline & $\mathrm{NH}_{4}^{+}$ & $\mathrm{NO}_{3}^{-}$ & $\mathrm{NH}_{4} \mathrm{NO}_{3}$ & $10-99$ & -37.008 & 141.284 & -263.06 & 227.336 & -68.736 & & & \\
\hline & $\mathrm{NH}_{4}^{+}$ & $\mathrm{Cl}^{-}$ & $\mathrm{NH}_{4} \mathrm{Cl}$ & $10 \leq \mathrm{RH}<20$ & -8.2548 & 13.1236 & & & & & & \\
\hline & & & & $20 \leq \mathrm{RH} \leq 99$ & -4.5036 & -9.3076 & 18.9844 & -5.1924 & & & & \\
\hline & $\mathrm{Na}$ & $\mathrm{SO}_{4}^{2-}$ & $\mathrm{Na}_{2} \mathrm{SO}_{4}$ & $10-99$ & 2.7561 & -109.26 & 566.466 & -1637.28 & 2615.1 & -2151.78 & 713.22 & \\
\hline & $\mathrm{Na}$ & $\mathrm{NO}_{3}^{-}$ & $\mathrm{NaNO}_{3}$ & $10 \leq \mathrm{RH}<20$ & -10.3092 & 19.3824 & & & & & & \\
\hline & & & & $20 \leq \mathrm{RH} \leq 99$ & -7.8764 & 7.1672 & -1.55868 & 2.3856 & & & & \\
\hline & $\mathrm{Na}$ & $\mathrm{Cl}^{-}$ & $\mathrm{NaCl}$ & $\begin{array}{l}10 \leq \mathrm{RH}<20 \\
20 \leq \mathrm{RH} \leq 99\end{array}$ & $\begin{array}{l}-5.5924 \\
-6.4404\end{array}$ & $\begin{array}{c}2.0798 \\
6.6156\end{array}$ & & & & & & \\
\hline
\end{tabular}

${ }^{a}$ The primary compound $\left(\mathrm{HHSO}_{4}\right.$ or $\left.\mathrm{H}_{2} \mathrm{SO}_{4}\right)$ or compound for which activity coefficient data are required is given in the left hand column, the 'interacting' compound, represented by the combinations of ions displayed in the second column, is displayed in the third column. The range of RH for which the coefficients are valid is given in the third column.

sensitive to an initial guess, an initial distribution was created using a normal distribution random number generator centered on zero. This was run 1000 times for each matrix of values for a given relative humidity providing partial derivatives for each solute as a function of relative humidity. Please note that using the above procedure it is straightforward to include solid formation. Since the thermodynamic model ADDEM is used to populate a matrix of activity coefficients for $\mathrm{H}^{+}, \mathrm{Na}^{+}, \mathrm{NH}_{4}^{+}, \mathrm{HSO}_{4}^{-}, \mathrm{SO}_{4}^{2-}, \mathrm{NO}_{3}^{-}$and $\mathrm{Cl}^{-}$we can calculate the activity coefficient of any combination of the above set, including electrolytes such as $\left(\mathrm{NH}_{4}\right)_{2} \mathrm{SO}_{4},(\mathrm{Na})_{2} \mathrm{SO}_{4}$, $\left(\mathrm{NH}_{4}\right)_{3} \mathrm{H}\left(\mathrm{SO}_{4}\right)_{2}$ etc. Given the required flexibility to include organic components, the lack of data describing inorganicorganic interactions and the likelihood that realistic ambient multicomponent aerosol particles will be liquid, solid phases will not be included in PD-FiTE.

[20] In order to investigate the required resolution (and hence data requirement) for the optimized fits to the partial derivatives, the fitting procedure was carried out across composition subdomains with different spacings. The following example focuses on the partial derivatives required for calculations of $\ln \gamma_{\mathrm{HNO} 3}$. To analyze the resolution required the granularity of the composition space was varied using 3 different logarithmic increments between the molar ratio of the condensing gas to other aqueous solutes (1) 100:1, 1:100; (2) $100: 1,1: 1,1: 100$; (3) 100:1, 10:1, 1:1, 1:10, 1:100) and one highly resolved data set using a linear increment (4) 100:1, $90: 1,80: 1 \ldots .1: 80,1: 90,1: 100)$. Thus for case a we have 21,780 data points whereas for case $d$ we have 119,790 data points. For either resolution no change in the form of the interaction parameters were found above an $\mathrm{RH}$ of $40 \%$. Even below $40 \%$, only a noticeable change was reported for case a for interactions with the salt $\mathrm{NaNO}_{3}$. In either case, the interaction parameters reported here are given for case $\mathrm{d}$

\subsection{Bisulfate Dissociation}

[21] In PD-FiTE, the impact of dissociation on the calculated activity coefficients is already accounted for by fitting partial derivatives over the entire composition space using ADDEM. However, a method for calculating actual concentrations of $\mathrm{H}^{+}$is required for expressions (3), (4) and (5). This must not be iterative so as to avoid associated computational burden. The molar ratio of $\mathrm{HSO}_{4}$ to $\mathrm{SO}_{4}$ is given by [Seinfeld and Pandis, 1998]

$$
\frac{m_{\mathrm{HSO}_{4}^{-}}}{m_{\mathrm{SO}_{4}^{2-}}}=\frac{1}{K_{\mathrm{HSO} 4}(T)} \frac{\gamma_{\mathrm{H}^{+}, \mathrm{SO}_{4}^{2-}}^{2}}{\gamma_{\mathrm{HSO}_{4}^{-}}} m_{H^{+}}
$$

Table 5. Coefficients for Polynomial Fits for Calculating $\ln \gamma^{o}(R H)$ for the Compounds Listed in the Left Hand Column ${ }^{\mathrm{a}}$

\begin{tabular}{|c|c|c|c|c|c|c|}
\hline Compound & RH Range (\%) & B0 & $\mathrm{B} 1$ & $\mathrm{~B} 2$ & B3 & B4 \\
\hline \multirow[t]{5}{*}{$\mathrm{HNO}_{3}$} & $10-40$ & 0.12091 & 13.497 & -67.771 & 144.01 & -117.97 \\
\hline & $40-90$ & 1.3424 & -0.8917 & -0.52983 & -0.37355 & $\ldots$ \\
\hline & $90-99$ & -1420.5 & 4467.9 & -4682.7 & 1635.1 & $\ldots$ \\
\hline & $40-90$ & 5.0147 & -8.3456 & 5.8914 & -2.9843 & $\ldots$ \\
\hline & $90-99$ & -1301.7 & 4096.5 & -4292.8 & -4.9943 & $\ldots$ \\
\hline $\mathrm{HHSO}_{4}$ & $10-99$ & 2.6875 & -11.832 & 20.601 & -18.593 & $\ldots$ \\
\hline \multirow{3}{*}{$\mathrm{H}_{2} \mathrm{SO}_{4}$} & $10-40$ & 1.3071 & -2.1559 & -3.5227 & 2.7718 & $\ldots$ \\
\hline & $40-90$ & 1.3071 & -2.1559 & -3.5227 & 2.7718 & $\ldots$ \\
\hline & $90-99$ & -395.18 & 1333.7 & -1504 & 564.63 & . \\
\hline
\end{tabular}

${ }^{\mathrm{a}}$ The RH range for which these coefficients apply to is given in the second column. All values were derived from values taken from AIM online. Functions are given in the form: $\ln \gamma^{o}(\mathrm{RH})=B o+B 1 * \mathrm{RH}+B 2 * \mathrm{RH}^{2}+B 3 * \mathrm{RH} 3+\ldots$ 


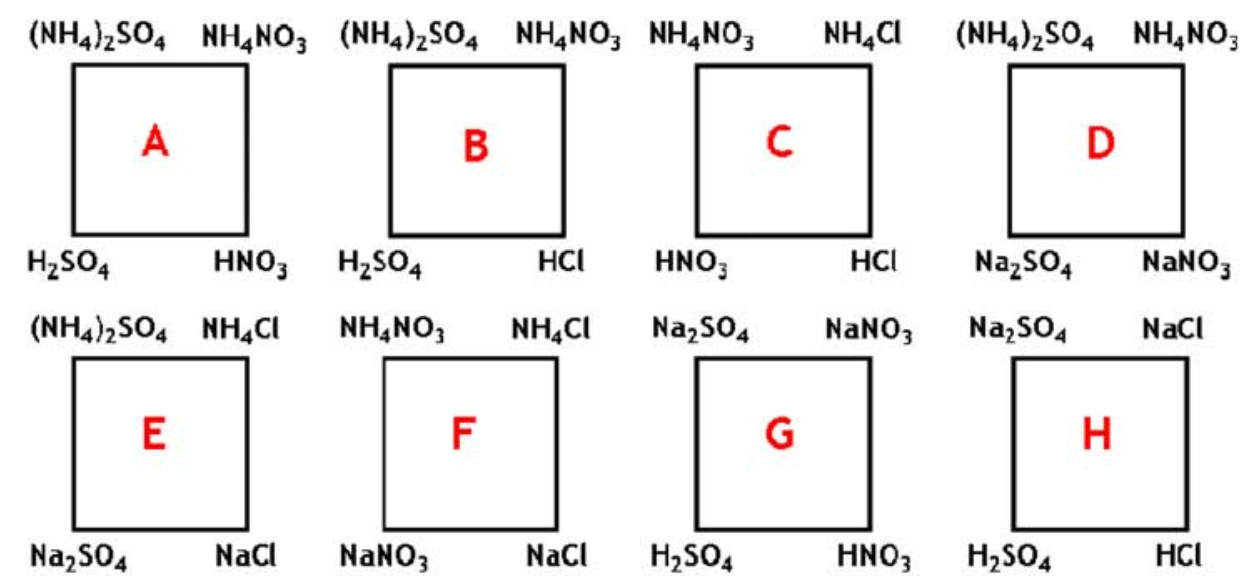

Figure 1. The eight $2 \mathrm{D}$ composition subspaces used in fitting the reduced framework across the entire composition space for the system $\mathrm{H}-\mathrm{NH}_{4}-\mathrm{Na}-\mathrm{SO}_{4}-\mathrm{NO}_{3}-\mathrm{Cl}$. Each apex represents a different electrolyte, the ratio between each one changing as the $x$ and $y$ coordinates change across each subspace.

where $K_{\text {HSO4 }}(\mathrm{T})$ is equilibrium constant $\left(1.01 \times 10^{-2}(\mathrm{~mol}\right.$ $\mathrm{kg}^{-1}$ ) at $298 \mathrm{~K}$ [Seinfeld and Pandis, 1998]). The temperature dependence of $\mathrm{K}_{\mathrm{HSO} 4}(\mathrm{~T})$ is discussed in section 5 . The total $\mathrm{SO}_{4}^{2-}$ and $\mathrm{H}^{+}$concentrations must be related to those defined in (23). This is achieved using the relationships

$$
\begin{gathered}
N_{\mathrm{SO}_{4}}=\left(N_{\mathrm{SO}_{4} \text { total }}-N_{\mathrm{HSO}_{4}}\right) \\
N_{H}=\left(N_{\text {Hotal }}-N_{\mathrm{HSO}_{4}}\right)
\end{gathered}
$$

where $N_{\mathrm{SO}_{4}}$ total and $N_{\text {Htotal }}$ are the total sulfate and hydrogen ion concentrations used in calculating the concentration of predefined electrolytes in PD-FiTE. Substituting (24) and (25) into (23) and rearranging one can arrive at a quadratic expressing the actual concentrations of $\mathrm{HSO}_{4}$.

$$
\begin{aligned}
& N_{\mathrm{HSO}_{4}}^{2}-N_{\mathrm{HSO}_{4}}\left[N_{\mathrm{SO}_{4} \text { total }}+N_{H, \text { total }}+\frac{N_{\text {water }} M_{\text {water }}}{99 \frac{\gamma_{H^{+}, \mathrm{SO}_{4}^{2-}}^{2}}{\gamma_{\mathrm{HSO}_{4}^{-}}}}\right] \\
& +N_{S_{4} \text { total }} N_{H, \text { total }}=0
\end{aligned}
$$

and the actual concentration of $\mathrm{HSO}_{4}^{-}$can be found by finding the positive solution to (26). To calculate the activity coefficient ratio between $\mathrm{H}^{+}, \mathrm{SO}_{4}^{2-}$ and $\mathrm{HSO}_{4}^{-}$the following relationship is used [Zaveri et al., 2005].

$$
\frac{\gamma_{\mathrm{H}} \gamma_{\mathrm{SO}_{4}}}{\gamma_{\mathrm{HSO}_{4}}}=\frac{\gamma_{\mathrm{H}_{2} \mathrm{SO}_{4}}^{3}}{\gamma_{\mathrm{HHOO}_{4}}^{2}}
$$

[22] As in previous sections, partial derivatives have been fitted to provide parameterizations for $\gamma_{\mathrm{H}_{2} \mathrm{SO}_{4}}^{3}$ and $\gamma_{\mathrm{HHSO}_{4}}^{2}$ using the same procedure as fitting the model to $\left(\frac{\gamma_{N H_{4}^{+}}}{\gamma_{H^{+}}}\right)$. In PD-FiTE this is not constrained to sulfate rich systems and the polynomials used to calculate equation (26) are applicable across both sulfate-poor and sulfate-rich systems. The accuracy of this approach discussed in section 6 .

\subsection{Water Content}

[23] For a basic calculation of water content in an aqueous aerosol, neglecting any solid formation of gas-aerosol equilibration, the well known Zdanovski-Robinson-Stokes (ZSR) mixing rule [Stokes and Robinson, 1966] can be used. The generalized form presented in most publications [e.g., Jacobson et al., 1996] is given by (21).

$$
W=\sum \frac{M_{i}}{m_{i o}\left(a_{w}\right)}
$$

$W$ is the total water content, $M_{i}$ is the mass of the solute present and $\mathrm{m}_{\mathrm{io}}\left(\mathrm{a}_{\mathrm{w}}\right)$ the molality at a given $\mathrm{RH}\left(\mathrm{a}_{\mathrm{w}}\right)$. In principle the ZSR relationship can be applied to any number of systems, including organic mixtures, as only water activity data from single electrolytes is required. If such binary data are not available for a given system, this precludes its use in predictive models. This may be the case when considering the water-soluble aerosol organics using representative compounds and this is the subject of a separate study. Coefficients for polynomials of mole fraction of water for the electrolytes given in Table 2 are given in Table 6.

\section{Temperature Dependence}

[24] Including a temperature dependence for the inorganic species considered in this study requires temperaturedependent mean binary activity coefficients, Taylor series partial derivatives and Henry's law constants. These are discussed in the sections 5.1 and 5.2 below.

\subsection{Activity Coefficients}

[25] While we retain our analysis, thus provision of a generic framework, to $298.15 \mathrm{~K}$, there are routes for including any temperature dependence into PD-FiTE. The empirical parameterizations of activity coefficients employed within EQSAM [Metzger et al., 2002a, 2002b] or MTEM [Zaveri et al., 2005], do not include any temperature dependence. 
Table 6. Relative Concentrations of Ions Used as a Basis for the Eight Sulfate-Poor Test Cases ${ }^{\mathrm{a}}$

\begin{tabular}{cccccc}
\hline & \multicolumn{5}{c}{ Sulfate-Poor Domain } \\
\cline { 2 - 6 } & $\mathrm{NH}_{4}$ & $\mathrm{Na}$ & $\mathrm{SO}_{4}$ & $\mathrm{NO}_{3}$ & $\mathrm{Cl}$ \\
\hline 1 & 11 & $\ldots$ & 5 & 1 & $\ldots$ \\
2 & 4 & $\ldots$ & 1 & 2 & $\ldots$ \\
3 & $\ldots$ & 12 & 1 & $\ldots$ & 10 \\
4 & $\ldots$ & 5 & 2 & $\ldots$ & 1 \\
5 & 11.5 & 2 & 6 & 1 & 0.5 \\
6 & 7 & 3.4 & 2 & 6 & 0.4 \\
7 & 1 & 8 & 1 & 1 & 6 \\
8 & 3 & 11.4 & 6 & 2 & 0.4 \\
\hline
\end{tabular}

${ }^{\mathrm{a}}$ Extra amounts of $\mathrm{HNO}_{3}$ or $\mathrm{HCl}$ are added according to the molar ratios listed in the text.

However, as stated by Ansari and Pandis [1999], Clegg et al. [1996] showed that the solute activity of aqueous $\left(\mathrm{NH}_{4}\right)_{2} \mathrm{SO}_{4}$ varied by as much as $5 \%$ over the temperature range of $0-$ $50^{\circ} \mathrm{C}$. In the PSC activity coefficient model, interaction parameters have been derived over a range of tropospheric temperatures [Clegg et al., 1998b]. The authors state that the model is valid from 328 to $<200 \mathrm{~K}$ dependent on the liquidphase composition. In this body of work we have utilized the 298.15 K PSC model within ADDEM, allowing us to include the ions $\mathrm{Na}^{+}$and $\mathrm{Cl}^{-}$. In order to derive temperaturedependent interaction parameters within the framework presented above requires the use of an activity coefficient model which covers a range of temperatures. It is possible to include a temperature dependence using two approaches which are now briefly discussed. Please note however that for the remainder of the discussion, activity coefficient results are constrained to $298.1 \mathrm{~K}$, as are the provision of binary activity coefficients and partial derivatives. Firstly, for $\mathrm{HNO}_{3}$ and $\mathrm{HCl}$, PD-FiTE requires the evaluation of the binary activity coefficients $\ln \gamma_{H N O_{3}}^{o}(R H)$ and $\ln \gamma_{H C l}^{o}(R H)$. In order to calculate $\ln \gamma_{\mathrm{HNO}_{3}}^{o}(R H, T)$ and $\ln \gamma_{\mathrm{HCl}}^{o}(R H, T)$ one can use the polynomials provided by Jacobson [1999] or derive fits from the temperature-dependent version of AIM online. Using this approach one neglects temperature-dependent interactions between solutes in solution. Secondly, one would expect to require a temperature-dependent expansion of the Taylor Series Partial derivatives. To capture the second variation one would have to analyze data from a range of ternary systems which capture interactions between every binary solute (e.g., $\mathrm{NaCl}-\left(\mathrm{NH}_{4}\right)_{2} \mathrm{SO}_{4}$ or $\left.\mathrm{NH}_{4} \mathrm{Cl}-\mathrm{H}_{2} \mathrm{SO}_{4}\right)$ and extend the binary interaction parameter fits as a function of temperature as well as relative humidity. Since temperature-dependent data for some systems is limited, a range of sources and different activity coefficient models are required for this purpose, be it the PSC model or Pitzer's method. Providing a temperature dependence for the equilibrium vapor pressure of $\mathrm{NH}_{3}$ is more difficult, as is calculating the dissociation of the bisul-

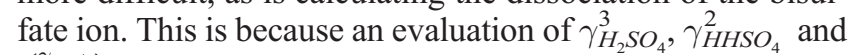
$\left(\frac{\gamma_{\mathrm{NH}_{4}^{+}}}{\gamma_{H^{+}}}\right)$is required. In PD-FiTE, for $\mathrm{NH}_{3}$, we have removed the need for binary activity coefficient calculations to evaluate all three of these variables in order to improve computational performance. Thus including a temperature dependence for these variables demands an extension of the relevant interaction parameters using the procedure described above. A more detailed sensitivity analysis to this dependence will be carried out in a future publication.

\subsection{Henry's Law and Dissociation Constants}

[26] The temperature dependence of an equilibrium constant $(K)$ can be represented using the van't Hoff equation.

$$
\frac{d \ln K}{d T}=\frac{\Delta H^{\theta}}{R T^{2}}
$$

where $\Delta H^{\theta}$ is the enthalpy of change and $R$ is the gas constant. By assuming the enthalpy of change is constant with temperature, and knowledge of the value of $K\left(T_{0}\right)$ at a temperature $T_{0}$, the integral of equation (29) can be used to calculate $K$ for any temperature.

$$
K=K\left(T_{0}\right) \times \exp \left(\frac{-\Delta H^{\theta}}{R}\left(\frac{1}{T}-\frac{1}{T_{0}}\right)\right)
$$

[27] This method of representing temperature dependence can be applied to both Henry's law and ion dissociation constants. In Table 1 we present the $K\left(T_{0}\right)$ and ${ }^{-} \Delta H^{\theta} / R$ values for the relevant equilibrium constants used in PD-FiTE, using a $T_{0}$ of $298.15 \mathrm{~K}$.

\section{Results and Discussion}

[28] The following section presents the ability of the current parameterization to reproduce activity coefficients (section 6.1) and bisulfate dissociation (section 6.2) across multiple composition regimes and relative humidities. In section 6.3 we review the computational cost of PD-FiTE. For calculations of water content the ability of the ZSR mixing rule has been extensively reviewed in the literature and is not repeated here.

\subsection{Activity Coefficients}

[29] In the following section predictions are made for $\gamma_{\mathrm{HNO} 3}, \gamma_{\mathrm{HCl}}$ and $\left(\frac{\gamma_{N H 4}}{\gamma_{H}}\right)$. While comparative statistics are drawn over a broad range of compositions and relative humidities to probe the full applicability of reduced frameworks, regimes potentially more "relevant" for tropospheric aerosol provide the focus. For ease of comparison, the sulfaterich and sulfate-poor domains of Zaveri et al. [2005], as presented in Table 7, have been used as proxies for compositions in a variety of environments. This is particularly useful since they conducted a comprehensive comparison between MTEM, Bromley's method, the Kusik and Meisner's mixing rule and the PSC activity coefficient model across these regimes. Initially, for a broad and thorough comparison, 5 different molar ratios of a condensing gas $\mathrm{HX}$ to other aqueous solutes were studied. These were taken as 1:100, 1:10, 1:1, 10:1 and 100:1 and are used solely to probe as much of the composition space as possible while remaining concise. Thus, for example, one might take case 2 presented in Table 6 and vary the molar ratio of $\mathrm{HNO}_{3}$ to the total number of salts using the above ratios. While this provides an indication of where each model is particularly applicable, one specific molar concentration test case has been chosen for particular attention. "Free" $\mathrm{HNO}_{3}$ and $\mathrm{HCl}$ are usually present in very small quantities in both sulfate-poor and sulfate-rich systems. Thus, for realistic aerosol, mixed particles with 1:100 ratio of HX to other aqueous solutes as presented in Figure 2 have been 
Table 7. Relative Concentrations of Ions $\mathrm{NH}_{4}, \mathrm{Na}$, and $\mathrm{SO}_{4}$ for Eight Sulfate-Rich Test Cases ${ }^{\mathrm{a}}$

\begin{tabular}{lcc}
\hline & \multicolumn{2}{c}{ Sulfate-Rich Domain } \\
\cline { 2 - 3 } $\mathrm{Xt}$ & $\mathrm{NH}_{4}+\mathrm{Na}$ & $\mathrm{SO}_{4}$ \\
\hline 0.3 & 0.3 & 1 \\
0.5 & 0.5 & 1 \\
0.7 & 0.7 & 1 \\
0.9 & 0.9 & 1 \\
1.1 & 1.1 & 1 \\
1.3 & 1.3 & 1 \\
1.5 & 1.5 & 1 \\
1.7 & 1.7 & 1 \\
\hline
\end{tabular}

${ }^{\mathrm{a}}$ In each case, the total concentration of $\mathrm{NH}_{4}$ and $\mathrm{Na}$ relative to $\mathrm{SO}_{4}$ defines the sulfate ratio Xt. The $\mathrm{NH}_{4}: \mathrm{Na}$ ratio is varied for each $\mathrm{Xt}$ value in the manner described in the text.

investigated. Here, the PD-FiTE model has been compared with MTEM and the PSC activity coefficient model as a benchmark. Firstly, for a broad comparison between models, Table 9 provides average absolute deviations between predictions of $\gamma_{\mathrm{HNO}_{3}}, \gamma_{\mathrm{HCl}}$ and $\left(\frac{\gamma_{\mathrm{NH}_{4}^{+}}}{\gamma_{H^{+}}}\right)$across varying composition spaces. For $\gamma_{\mathrm{HNO}_{3}}$ and $\gamma_{\mathrm{HCl}}$ the relative humidity range of $40-99 \%$ was used, whereas for $\left(\frac{\gamma_{\mathrm{NH}_{4}^{+}}}{\gamma_{H^{+}}}\right)$an upper limit of $30 \%$ was employed for a fair test between both parameterizations in sulfate-rich regimes. Results suggest that over the entire composition space, the PD-FiTE model has an average deviation of 19.28 and $50.19 \%$ from those
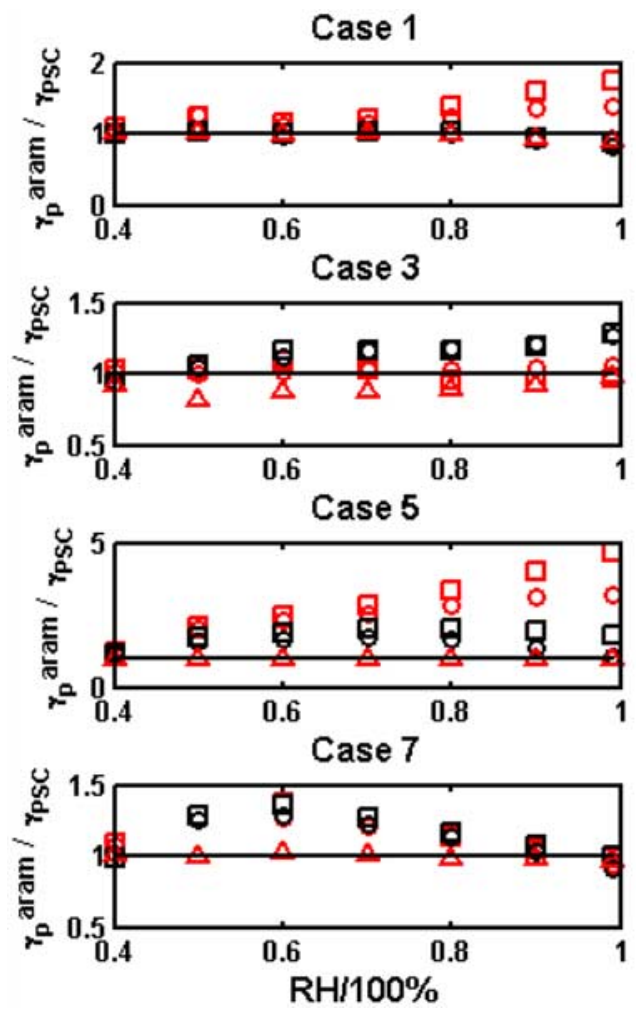

calculated using the PSC model, for $\gamma_{\mathrm{HCl}}$ and $\gamma_{\mathrm{HNO}_{3}}$ respectively, compared with 23.67 and $46.49 \%$ for MTEM. Apart from case study 5, the deviations between MTEM and PSC tend to increase as the gas: aerosol molar ratio increases beyond 1:10. To highlight specific test cases, in Figure $2 \gamma_{\mathrm{HNO}_{3}}$ and $\gamma_{\mathrm{HCl}}$ are calculated using this model and MTEM and then compared with $\gamma_{\mathrm{HNO}}$ and $\gamma_{\mathrm{HCl}}$ calculated using the implementation of the PSC activity coefficient model within ADDEM (denoted "ADDEM"). In this instance we use the same PSC parameter basis set employed in the $298.15 \mathrm{~K}$ version of AIM online (S. Clegg, personal communication, 2004). Specifically, comparisons are made with 1:100 ratio of $\mathrm{HX}$ to other aqueous solutes and are given in the form

$$
\frac{\gamma_{\text {calculated }}}{\gamma_{A D D E M}}
$$

[30] Both models reproduce $\gamma_{H N O_{3}}$ very well yet results are system-dependent. PD-FiTE appears to be more accurate for $57.5 \%$ of the conditions within these specific test cases. For example, in cases 3 and 4, designed as a proxy for freshly emitted and aged sea-salt aerosol, PD-FiTE compares favorably with ADDEM over most ambient conditions. However, in test case 1, for example, which represents an urban aerosol with a dominance of sulfate over nitrate, MTEM performs favorably. This is also evident in Figure 2, where the model predictions for $\gamma_{\mathrm{HNO}_{3}}$ do not deviate very far from the PSC model, particularly for test cases 3 and 4. Interestingly,
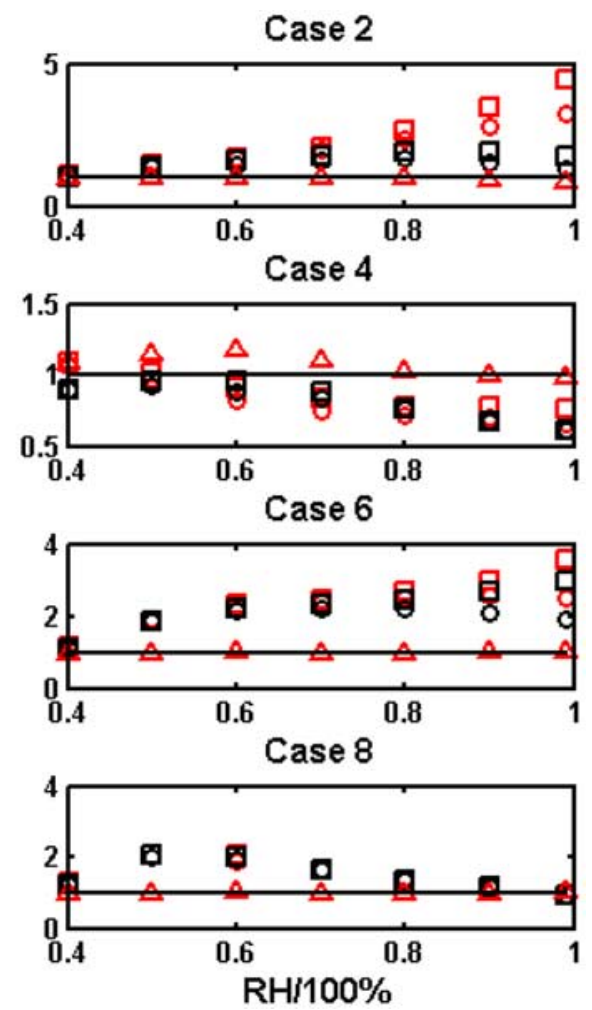

Figure 2. A comparison of calculated activity coefficients for $\mathrm{HNO}_{3}$ and $\mathrm{HCl}$ from both $\mathrm{MTEM}$ and PD-FiTE, with 1:100 ratio of HX to other aqueous solutes. Each subplot represents a different case study, as defined by Table 7 . The red symbols represent results from PD-FiTE, whereas the black symbols represent results from MTEM. Circles represent $\mathrm{HNO}_{3}$, whereas squares represent $\mathrm{HCl}$. The red triangles represent $\mathrm{PD}$-FiTE predictions for $\mathrm{HNO}_{3}$ when constrained to the composition space defined by the 1:100 ratio of $\mathrm{HX}$ to other aqueous solutes rather than a range of ratios. 

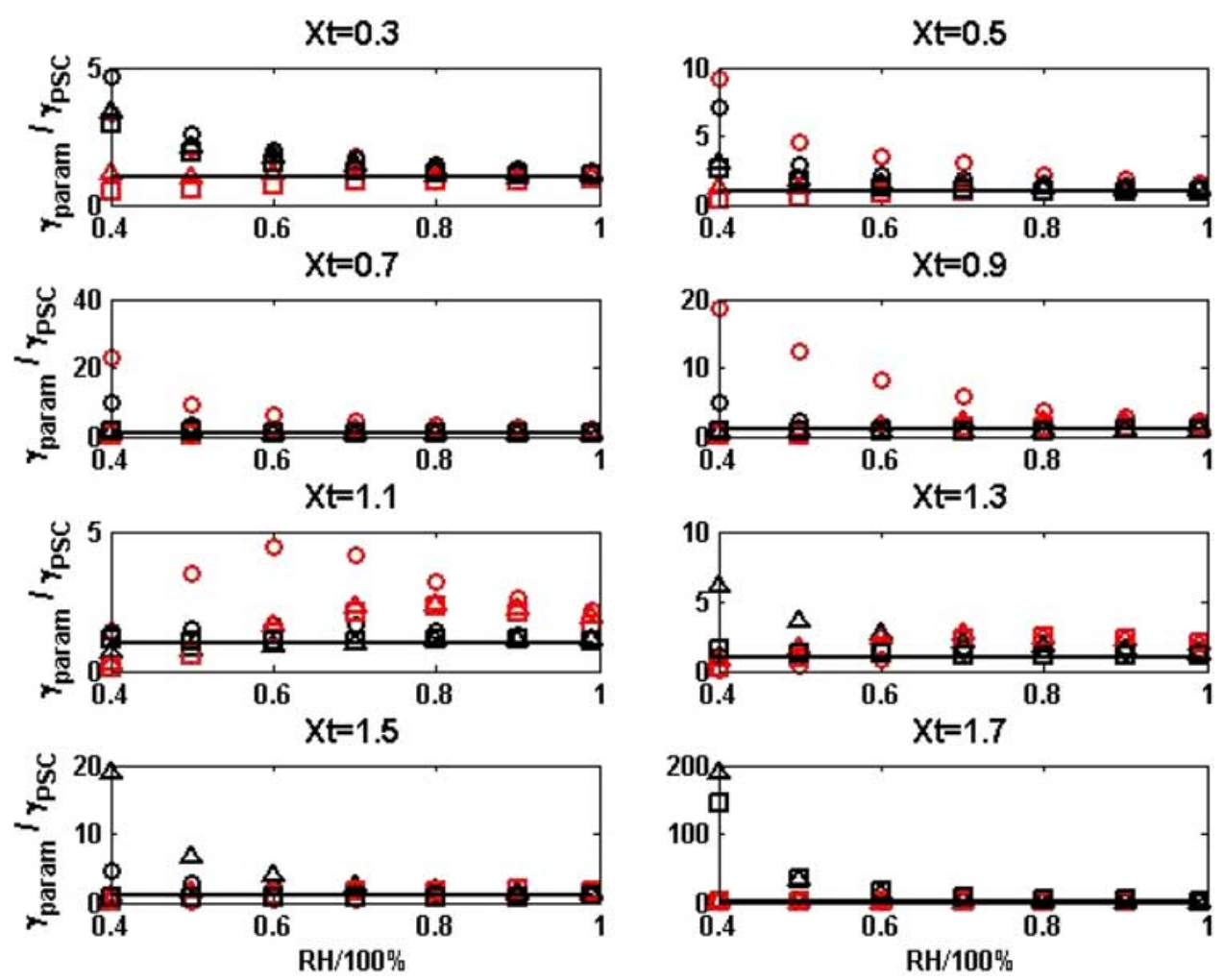

Figure 3. A comparison of calculated activity coefficients ratio for $\mathrm{H}^{+}$and $\mathrm{NH}_{4}^{+}$from both MTEM and PDFiTE for eight varying sulfate ratio $\mathrm{Xt}$, as defined in the text. Each graph highlights three different $\mathrm{NH}_{4}: \mathrm{Na}$ molar ratios (circle, triangle, and squares represent an $\mathrm{NH}_{4}: \mathrm{Na}$ ratio of 100:1, 1:1, and 1:100, respectively). The red lines represent results from PD-FiTE, whereas the black symbols represent results from MTEM.

beyond a relative humidity of $40 \%$, both models tend to deviate slightly from ADDEM. For $\gamma_{\mathrm{HCl}}$, comparisons are again systems-dependent. Again, in cases 3 and 4, PD-FiTE compares favorably with ADDEM over most ambient conditions. However, in test case 1, MTEM performs favorably. Interestingly, both models agree very well for both $\gamma_{\mathrm{HNO} 3}$ and $\gamma_{\mathrm{HCl}}$ in test cases 7 and 8 which are designed to represent coastal urban locations and marine environments downwind of large urban sources. Both cases are sodium rich with a dominance of sulfate over nitrate. PD-FiTE appears to be more accurate for $70 \%$ of the conditions within specific test cases. Again, results for the 1:100 ratio of $\mathrm{HX}$ to other aqueous solutes are presented in Figure 2.

[31] To calculate the vapor pressure of $\mathrm{NH}_{3}$ it is necessary to calculate $\left(\frac{\gamma_{\mathrm{NH}_{4}^{+}}}{\gamma_{H^{+}}}\right)$. The ability of each model to reproduce this ratio across sulfate-rich domains are shown in Figure 3. In this analysis the sulfate ratio Xt has been varied at values of $0.3,0.5,0.7,1.1,1.3,1.5$ and 1.7 using permutations of the $\mathrm{NH}_{4}^{+}-\mathrm{Na}^{+}-\mathrm{SO}_{4}^{2-}$ system as presented in Table 7. Similarly, following the approach of Zaveri et al. [2005], the ratio of $\mathrm{NH}_{4}^{+}$to $\mathrm{Na}^{+}$has also been varied attempting to probe as broad a composition as possible. As described in section 4.2, the calculation of $\left(\frac{\gamma_{N H_{4}^{+}}}{\gamma_{H^{+}}}\right)$has been simplified by using only one set of parameters for a given $\mathrm{RH}$, in comparison to two sets of parameters within MTEM. Table 8, again, provides an average percentage deviation across the sulfate-rich regimes by varying the ratio of $\mathrm{NH}_{4}^{+}$to $\mathrm{Na}^{+}$, between 30 and $99 \% \mathrm{RH}$. Both models have larger deviations compared with $\mathrm{HNO}_{3}$ and $\mathrm{HCl}$, however results suggest the model presented here has an average deviation of 53\% from the PSC prediction compared to $191 \%$ for MTEM. In order to elucidate on this, Figure 3 present results over all sulfate ratios, represented as

$$
\left(\frac{\gamma_{N H_{4}^{+}}}{\gamma_{H^{+}}}\right)_{\text {calculated }} /\left(\frac{\gamma_{N H_{4}^{+}}}{\gamma_{H^{+}}}\right)_{\text {ADDEM }}
$$

[32] The 3 symbols in each plot represent 3 different molar ratios of $\mathrm{NH}_{4}: \mathrm{Na}$ within each sulfate ratio (100:1, 1:1, 1:100). For Xt ratios of $0.3-0.5$, both models look very similar, with PD-FiTE slightly more accurate than MTEM. In systems with $\mathrm{Xt}=0.7$ and 0.9 , MTEM is more accurate than the PD-FiTE; again, both models perform very well, staying within the bounds of $0.8-2$ apart from at higher $\mathrm{NH}_{4}^{+}$to $\mathrm{Na}^{+}$ ratios at lower $\mathrm{RH}$. Interestingly, at these $\mathrm{Xt}$ ratios, while deviations are expected to increase at lower $\mathrm{RH}$, thus more concentrated solutions, it would appear that as the $\mathrm{NH}_{4}^{+}$to $\mathrm{Na}^{+}$ratio decreases, model predictions become slightly more accurate. Increasing the sulfate ratio even more, one can see that for systems with $\mathrm{Xt}=1.1$, MTEM provides more accurate results. For systems with $\mathrm{Xt}=1.3$ both models converge, particularly for smaller $\mathrm{NH}_{4}$ to $\mathrm{Na}$ ratios. For systems with $\mathrm{Xt}=1.5$ and $\mathrm{Xt}=1.7$ however, again, the model presented here is more accurate than MTEM, apart from at high $\mathrm{Na}^{+}: \mathrm{NH}_{4}^{+}$ratio in system with $\mathrm{Xt}=1.7$. Indeed, for the last system, MTEM tends to overpredict relationship (25) 
Table 8. Average Absolute Percentage Deviations Between MTEM and This Study, as Compared With a Thermodynamic Model ADDEM Using the PSC Activity Coefficient Model Across the Entire Composition Space and Selected RH Regimes

\begin{tabular}{lccc}
\hline & RH Range (\%) & MTEM & PD-FiTE \\
\hline$\gamma_{H C l}$ & $40-99$ & 23.67 & 19.28 \\
$\gamma_{H N O 3}$ & $40-99$ & 46.49 & 50.19 \\
$\frac{\gamma_{N H 4}}{\gamma_{H}}$ & $30-99$ & 191 & 53 \\
\hline
\end{tabular}

below $50 \%$ RH significantly. It would appear that for regions with 'midrange' $\mathrm{Xt}$ values, away from the sulfate-poorsulfate-rich boundary, the use of two separate sets of activity coefficients for $\left(\frac{\gamma_{N H_{4}^{+}}}{\gamma_{H^{+}}}\right)$can lead to an increase in accuracy. This is conceptually obvious as the number of degrees of freedom of the parameterization is increased. Thus increasing the parameterizations required for $\left(\frac{\gamma_{N H_{4}^{+}}}{\gamma_{H^{+}}}\right)$, using the fitting procedure described in section 4.2 , it is thus possible to not only increase the accuracy of the PD-FiTE model but also retain a high level of computational efficiency; this will be developed in further work.

\subsection{Bisulfate Dissociation}

[33] Using the same sulfate-rich domains as section 6.1, here the ratio of calculated $\mathrm{HSO}_{4}^{-}$amounts to those derived from the PSC model (Figure 4) are presented. It is worth noting that both models can reproduce the bisulfate ion dissociation very well; the accuracy of one model against the other being composition and RH-dependent. Across the entire composition and RH space, the PD-FiTE model and MTEM have average deviations of 4.8 and $6.7 \%$ compared against ADDEM. In many cases below a sulfate ratio of $\mathrm{Xt}=1$, this model appears more accurate below $50 \% \mathrm{RH}$, while in the mid RH regimes, MTEM compares favorably with ADDEM. Overall, as the $\mathrm{NH}_{4}: \mathrm{Na}$ ratio decreases for each value of $\mathrm{Xt}$ the deviation between both reduced frameworks and ADDEM tends to increase with discrepancies predominantly remaining within $15 \%$

[34] For both this model and MTEM it is necessary to calculate the ratio $\frac{\gamma_{\mathrm{H}^{+}} \gamma_{\mathrm{SO}_{4}^{2-}}}{\gamma_{\mathrm{HSO}_{4}^{-}}}$. In the above analysis, by varying the molar ratio of $\mathrm{NH}_{4}^{+}$to $\mathrm{Na}^{+}$and altering the sulfate ratio $\mathrm{Xt}$, in the PD-FiTE model one assumes the electrolytes $\left(\mathrm{NH}_{4}\right)_{2} \mathrm{SO}_{4}$, $\mathrm{Na}_{2} \mathrm{SO}_{4}$ and $\mathrm{H}_{2} \mathrm{SO}_{4}$ to form. Thus one has to consider the interactions between $\left(\mathrm{NH}_{4}\right)_{2} \mathrm{SO}_{4}$ and $\mathrm{Na}_{2} \mathrm{SO}_{4}$ with $\mathrm{HHSO}_{4}$ and $\mathrm{H}_{2} \mathrm{SO}_{4}$ individually, as well as calculating the binary activity coefficients for $\mathrm{HHSO}_{4}$ and $\mathrm{H}_{2} \mathrm{SO}_{4}$. This is the same across both sulfate-poor and all sulfate-rich regimes. In MTEM the electrolytes allowed to occur depends on the sulfate ratio Xt. Below 0.1, the electrolytes $\mathrm{H}_{2} \mathrm{SO}_{4}, \mathrm{NH}_{4} \mathrm{HSO}_{4}$ and $\mathrm{NaHSO}_{4}$ are allowed to form. In this instance, one
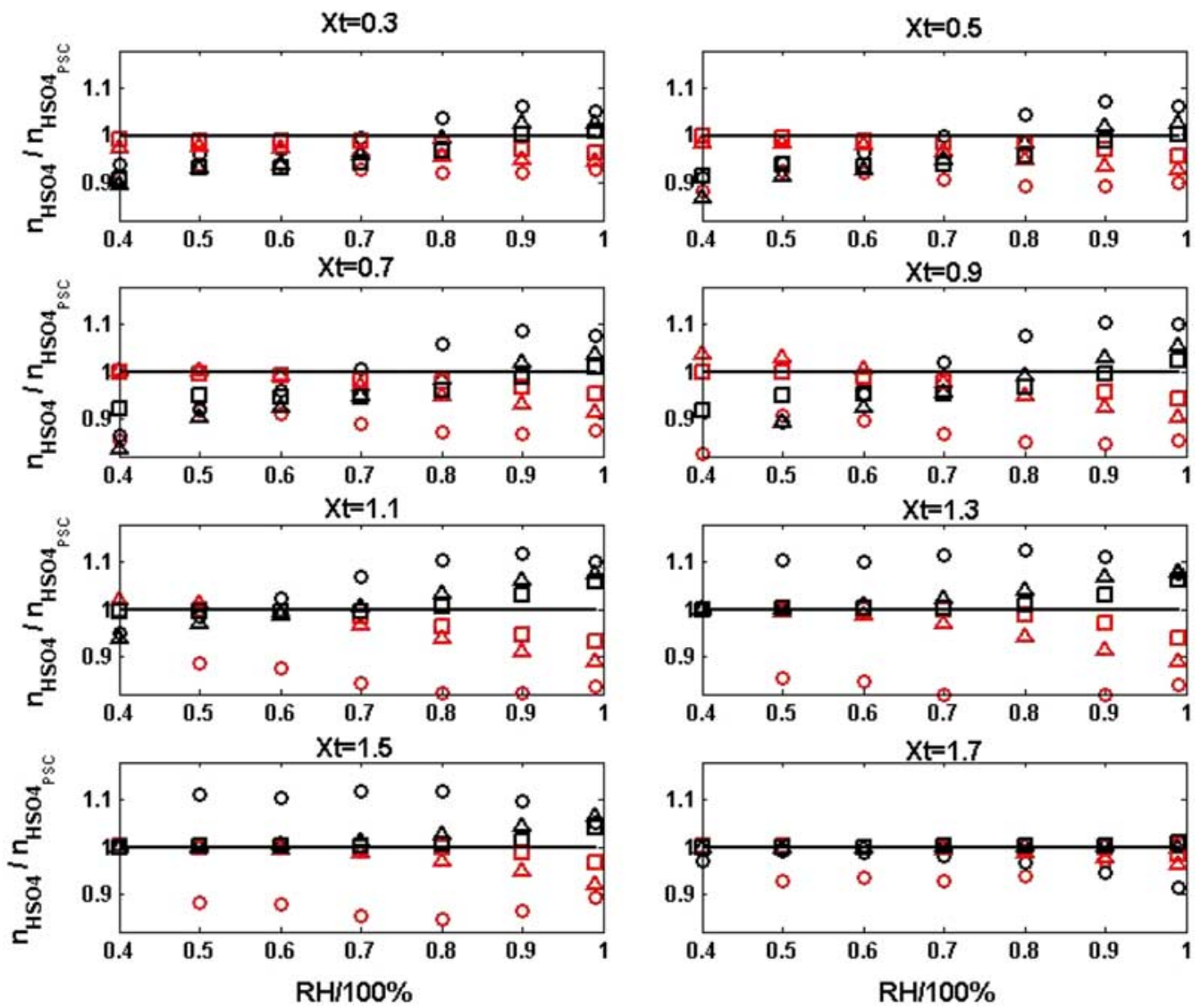

Figure 4. Comparison of calculated bisulfate ion concentrations from both MTEM. Each graph high-

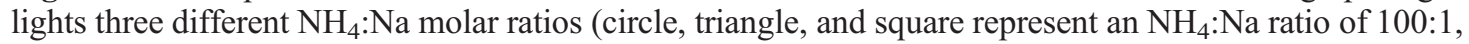
1:1, and 1:100 respectively). The red lines represent results from PD-FiTE, whereas the black symbols represent results from MTEM. 
has to calculate interactions between $\mathrm{H}_{2} \mathrm{SO}_{4}, \mathrm{NH}_{4} \mathrm{HSO}_{4}$ and $\mathrm{NaHSO}_{4}$.

\subsection{Sensitivity of Fitted Parameters Within PD-FiTE to Chosen Composition Space}

[35] When making a parameterization as broadly applicable as possible, it is necessary to use a broad basis set to fit to. If basis set is narrowed down, the range of applicability is reduced. In section 4.1 it was mentioned that Zaveri et al. [2005] choose specific concentrations of, for example $\mathrm{HNO}_{3}$ relative to other solutes, constrained by the assumption of the finite difference approximation within the Taylor Series expansion. More specifically, the parameters within MTEM are derived from limiting cases of, for example, electrolyte A in a ternary mixture of A-B- $\mathrm{H}_{2} \mathrm{O}$ [Zaveri et al., 2005]. In PD-FiTE however we use the entire composition space of $\mathrm{H}^{+}-\mathrm{NH}_{4}^{+}-\mathrm{Na}^{+}-\mathrm{SO}_{4}^{2-}-\mathrm{HSO}_{4}^{-}-\mathrm{NO}_{3}^{-}-\mathrm{Cl}^{-}$with varying ratios of condensing gas to other aqueous solutes to derive parameters. Thus all of the above comparisons are between two models using different basis sets. The approach within PD-FiTE is flexible in the sense that the parameter basis set can be constrained to any specific systems should an increase in accuracy be required for select cases. As an example, the partial derivatives for $\gamma_{\mathrm{HNO} 3}$ were again fit to the entire composition space of $\mathrm{H}^{+}-\mathrm{NH}_{4}^{+}-\mathrm{Na}^{+}-\mathrm{SO}_{4}^{2-}-\mathrm{HSO}_{4}^{-}-\mathrm{NO}_{3}^{-}-\mathrm{Cl}^{-}$ but restricted in relation to the ratio of condensing gas $\mathrm{HX}$ to other aqueous solutes, set between 1:100 and 1:10. Comparisons were then made with the 8 sulfate-poor test cases already described in section 6.1 and are presented in Figure 2 as triangles. Clearly, by constraining the fit parameters to specific concentration ratios, the deviations between PDFiTE and ADDEM drop significantly with an average value of $4.16 \%$, compared to $50.19 \%$ for the "full" model. Using these new parameters, PD-FiTE compares favorably with ADDEM for all test cases. A maximum deviation of $10.05 \%$ was found for test case 3, with values as low as $1.23 \%$ for test case 6 . This demonstrates how the ethos behind PD-FiTE can be used to tailor the efficient framework to specific scenarios.

\subsection{Computational Efficiency}

[36] All mixing rule parameterizations, which have been developed for use within three-dimensional atmospheric chemistry models, are much more computationally efficient than the ion interaction models of Pitzer and Simonson [1986] and Clegg et al. [1992]. Initially, however these parameterizations [e.g., Bromley, 1973; Kusik and Meissner, 1978] were all expressed as a function of ionic strength, and so would need to be reevaluated whenever the ionic strength changed, which would happen repeated within the iterative numerical methods which are typically used to determine gas-liquid/solid partitioning within three-dimensional models. The approach of expressing these parameterizations in terms of water activity (assuming $\mathrm{a}_{\mathrm{w}}=\mathrm{RH}$ ) instead [Metzger et al., 2002a, 2002b; Zaveri et al., 2005] reduces the computational cost of these iterations by enabling us to calculation the binary activity coefficients, $\gamma_{M X}$, only once per external model time step (as RH is usually assumed to remain constant over these time steps). This directly reduces the computational cost of each internal model iteration, and also allows a noniterative solution to be found for $m_{H^{+}}$, further reducing computation costs.
[37] Both Metzger et al. [2002a, 2002b] and Zaveri et al. [2005] have demonstrated how the adoption of this approach is more computationally efficient than using the Bromley's approach, so these efforts will not be duplicated here. Instead the computational costs of calculating the activity coefficients of $\mathrm{HNO}_{3}, \mathrm{HCl}, \mathrm{NH}_{3}$, and $\mathrm{HSO}_{4}^{-}$for any given $\mathrm{RH}$ - and condensed-phase $\mathrm{H}^{+}-\mathrm{NH}_{4}^{+}-\mathrm{Na}^{+}-\mathrm{SO}_{4}^{2-}-\mathrm{HSO}_{4}^{-}-\mathrm{NO}_{3}^{-}-\mathrm{Cl}^{-}$ composition will be determined. The processes that become more computationally important when splitting the calculations between external and internal time steps are examined in detail. To do this a typical computational scenario is considered, in which a sectional liquid aerosol model, with eight size bins, is run at a fixed $\mathrm{RH}$ within a single grid cell of a three-dimensional dynamical model, requiring 10 internal time step iterations for each external model time step. The computational cost of this process has been calculated analytically for both PD-FiTE and MTEM, and is presented in terms of floating point operations (FLOPS). The details of these calculations are given in Appendix A.

[38] The computational costs of PD-FiTE and MTEM are comparable, with PD-FiTE using $\sim 8.7 \mathrm{kFLOPs}$ for the above scenario, in comparison with MTEM which uses $\sim 6.5-12.3$ kFLOPs for the same scenario. Looking at the breakdown of these costs we see that the calculation of $\gamma_{M X}$, which is down once per external time step, costs from 420 to 560 FLOPS in PD-FiTE, depending on RH, compared with a cost of 1220 FLOPS in MTEM. This is because MTEM must calculate all values of $\gamma_{M X}$ for both their sulfate-rich and sulfate-poor domains, because, unlike RH, the state of the aerosols is not known a priori to the treatment of each aerosol size bin. This is, however, only $5-10 \%$ of the total computational costs for the scenario, for multiplying up the aerosol composition-specific costs for eight size bins and ten internal time steps soon overshadow the one-off computational costs of $\gamma_{M X}$.

[39] Focusing on differences in computational cost of the sulfate-rich and sulfate-poor domains used in MTEM, PD-FiTE is about $30 \%$ cheaper MTEM within the sulfatepoor domain. However it should be noted that this cost for PD-FiTE also includes the calculation of the activity coefficient for $\mathrm{HSO}_{4}^{-}$, which MTEM does not calculate in this region. PD-FiTE is not more expensive in this domain for two reasons: firstly because the activity coefficient for $\mathrm{NH}_{3}$ is calculated more efficiently, requiring only one set of binary activity coefficients to be added together; and secondly because the electrolyte composition calculations used within PD-FiTE are cheaper than those used by MTEM within this domain.

[40] Within the sulfate-rich domain, representing the atmospheric conditions observed down wind of coal-burning power stations for example, we find that MTEM is more computationally efficient as PD-FiTE, by between $5 \%$ and $25 \%$. This is due to the reduced number of electrolytes MTEM considers within these domains; reducing the cost of both determining the electrolyte composition of the aerosol and the summing up of binary activity coefficients to obtain the activity coefficients.

\section{Demonstration of the Use of PD-FiTE in Dynamical Simulation of Aerosol Composition}

[41] As a demonstration of the usefulness of PD-FiTE in describing the role of variation of particle composition in the 

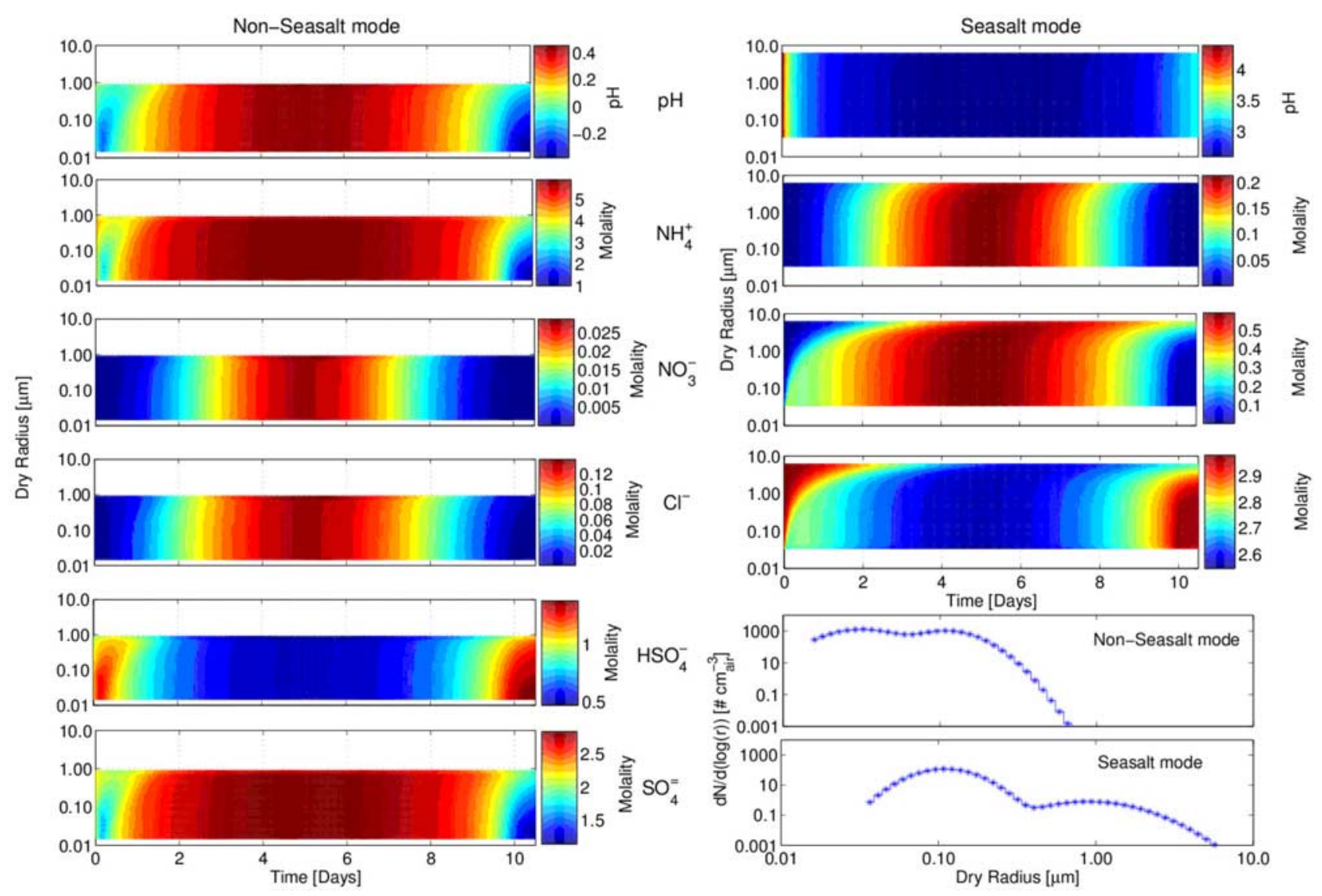

Figure 5. The upper eight plots the and the lower left two plots show the evolution of $\mathrm{pH}$ and the major ion molalities for the two aerosol modes over the model run. The $\mathrm{HSO}_{4}^{-}$and $\mathrm{SO}_{4}^{2-}$ contents of the seasalt mode are zero and so are not shown here. The lower right two plots show the initial number distributions for the externally mixed non-sea-salt and sea-salt modes.

dynamical evolution of an aerosol population, the code has been incorporated into a model describing the explicit disequilibrium mass transfer of semivolatile species to a developing aerosol size distribution. The model has been simplified to remove all gas-phase photochemistry so as to examine only the performance of the PD-FiTE module; a description of the model coupled to atmospheric oxidative gas-phase chemistry will be the subject of a future publication. The case study chosen here represents a relatively clean marine air mass being mixed with the oxidation products of anthropogenic gaseous pollutants before returning to a clean marine environment.

[42] PD-FiTE has been integrated into a combined chemistry-microphysical aerosol model; constructed using KPP [Damian et al., 2002]. In the full model all gas-phase and aerosol-phase reactions, as well as the transfer of mass between the gas and aerosol phases, are solved within the same time step using a third-order Rosenbrock solver. PD-FiTE is used to calculate the nonideal equilibrium constants for the dissociation of $\mathrm{HNO}_{3}, \mathrm{NH}_{3}, \mathrm{HCl}, \mathrm{H}_{2} \mathrm{SO}_{4}$ and $\mathrm{HSO}_{4}^{-}$, and the water content. The nonideal activity coefficients for the dissociation of $\mathrm{HNO}_{3}, \mathrm{NH}_{3}, \mathrm{HCl}, \mathrm{H}_{2} \mathrm{SO}_{4}$ and $\mathrm{HSO}_{4}^{-}$are given by $\gamma_{\mathrm{HNO}_{3}},\left(\frac{\gamma_{\mathrm{NH}_{4}^{+}}}{\gamma_{H^{+}}}\right), \gamma_{\mathrm{HCl}},\left(\frac{\gamma_{\mathrm{HHSO}_{4}}^{2}}{\gamma_{\mathrm{H}_{2} \mathrm{SO}_{4}}}\right)$ and $\left(\frac{\gamma_{\mathrm{H}_{2} \mathrm{SO}_{4}^{3}}}{\gamma_{\mathrm{HHSO}_{4}^{2}}}\right)$, respectively. The aerosol size distribution is represented in a sectional manner, using the Moving Centre method [Jacobson, 1997]. The component activity coefficients and semivolatile compo- nent vapor pressures for each section are calculated separately, as is the mass transfer from the gas-phase to each condensedphase section.

[43] The microphysical processes in the aerosol model are limited to condensation and evaporation only. The gas-phase species are: $\mathrm{HNO}_{3}, \mathrm{NH}_{3}, \mathrm{HCl}$, and $\mathrm{H}_{2} \mathrm{O}$. The aerosol species are: $\mathrm{Na}^{+}, \mathrm{H}^{+}, \mathrm{NH}_{4}^{+}, \mathrm{Cl}^{-}, \mathrm{NO}_{3}^{-}, \mathrm{HSO}_{4}^{-}, \mathrm{SO}_{4}^{2-}, \mathrm{OH}^{-}, \mathrm{HNO}_{3}$, $\mathrm{NH}_{3}, \mathrm{HCl}, \mathrm{H}_{2} \mathrm{SO}_{4}$ and $\mathrm{H}_{2} \mathrm{O}$. No gas-phase reactions are included, and the only condensed phase reactions considered are the dissociations of $\mathrm{HNO}_{3}, \mathrm{NH}_{3}, \mathrm{HCl}, \mathrm{H}_{2} \mathrm{SO}_{4}, \mathrm{HSO}_{4}^{-}$ and $\mathrm{H}_{2} \mathrm{O}$. The particle phase is composed of two externally mixed modes: a non-sea-salt mode with dry composition $32 \%\left(\mathrm{NH}_{4}\right)_{2} \mathrm{SO}_{4}, 64 \% \mathrm{NH}_{4} \mathrm{HSO}_{4}$, and $2 \% \mathrm{NH}_{4} \mathrm{NO}_{3}$; and a sea-salt mode with a dry composition of $100 \% \mathrm{NaCl}$ (note that the sea-salt mode is unbuffered since PD-FiTE currently cannot treat $\mathrm{CO}_{2}$ dissolution). The initial number distributions of the two modes are shown in the Figure 5 (the two plots in the lower right), the size range is discretized using 50 logarithmically spaced sections. Temperature and relative humidity are fixed at $285.15 \mathrm{~K}$ and $89.4 \%$ respectively. $\mathrm{HNO}_{3}$ and $\mathrm{NH}_{3}$ are fixed, initially at $1 \mathrm{ppt}$ respectively, but increasing sinusoidally to $100 \mathrm{ppt}$ and then back to concentrations of 1 ppt each over a period of 10 days. $\mathrm{HCl}$ is initialized at $0 \mathrm{ppt}$, increasing in response to the forcing from $\mathrm{HNO}_{3}$ and $\mathrm{NH}_{3}$ (as shown by the black lines in Figure 6), the uptake of which onto the sea-salt mode results in the out gassing of 

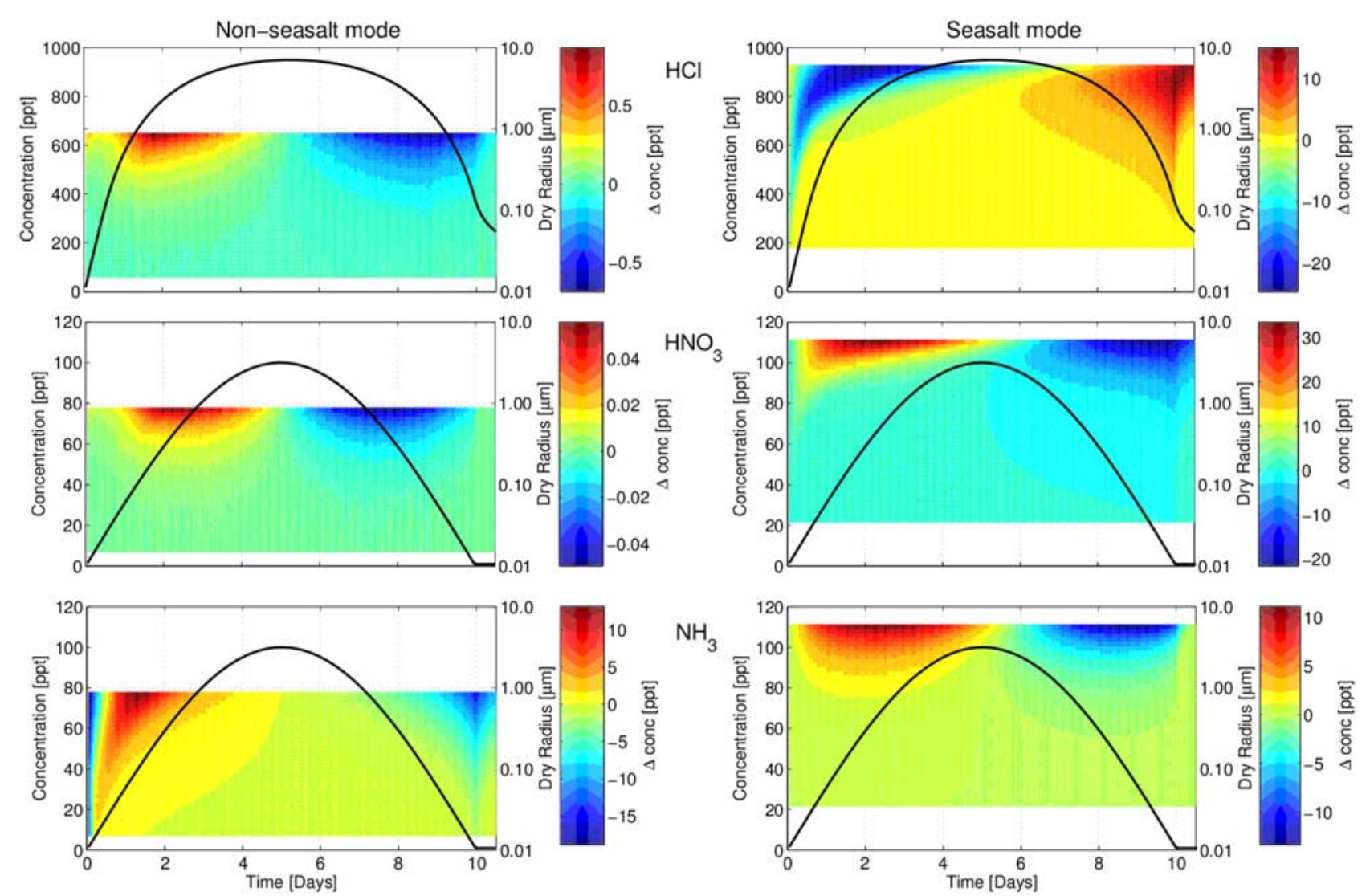

Figure 6. The colored surface plots show the differences between partial pressure and vapor pressure across the size ranges of the two aerosol modes for each semivolatile gas species (plotted as the difference in gas-phase concentrations in parts per trillion; red indicates higher partial pressures; blue indicates higher vapor pressures). The black lines show the absolute gas phase concentrations in parts per trillion of each semivolatile gas species during the model run. In each plot, the left axis shows the absolute concentrations for the black lines, whereas the right axis shows the dry particle radius for the colored surface plots. The initial and final concentrations of $\mathrm{HNO}_{3}$ and $\mathrm{NH}_{3}$ are given in the text.

$\mathrm{HCl}$, and it's reabsorption and outgassing by both the nonsea-salt and sea-salt modes. $\mathrm{HCl}$ concentration increases to a maximum of $950 \mathrm{ppt}$ once the $\mathrm{HNO}_{3}$ and $\mathrm{NH}_{3}$ concentrations reach their maxima. Once $\mathrm{HNO}_{3}$ and $\mathrm{NH}_{3}$ reach their initial conditions again the gas-phase $\mathrm{HCl}$ concentration slowly reduces to below $150 \mathrm{ppt}$ over another 5 days (not shown).

[44] In the sea-salt mode the molalities of $\mathrm{NO}_{3}^{-}$and $\mathrm{NH}_{4}^{+}$ increase with increasing $\mathrm{HNO}_{3}$ and $\mathrm{NH}_{3}$ gas-phase concentrations, while the molality of $\mathrm{Cl}^{-}$decreases over the same time and the aerosol becomes more acidic (Figure 5). There is also a time lag in the response of the largest particles to the changing conditions, due to their larger volume to surface area ratios. These slow changes in composition lead to large differences between the partial and vapor pressures of $\mathrm{HNO}_{3}$ and $\mathrm{HCl}$ over these large sea-salt particles (Figure 6). There are variations across the particle size range in the vapor pressure of $\mathrm{NH}_{3}$ too, though the differences between the partial and vapor pressures of $\mathrm{NH}_{3}$ are much smaller than the differences for $\mathrm{HNO}_{3}$ and $\mathrm{HCl}$. In the non-sea-salt mode all ionic species shown increase in molality with increasing $\mathrm{HNO}_{3}, \mathrm{NH}_{3}$, and $\mathrm{HCl}$ gas-phase concentrations, the aerosol also becomes less acidic. There is also no major composition dependence on particle size. The differences between the partial and vapor pressures of $\mathrm{HNO}_{3}$ and $\mathrm{HCl}$ over the nonsea-salt mode are very small, with some variation across the particle size range. The variation in the $\mathrm{NH}_{3}$ vapor pressures over the non-sea-salt mode is greater: with the vapor pressures over larger particles at the start and end of the pollution event differing significantly from the partial pressure. The magnitude of the differences between the partial and vapor pressures over the condensed phase for both aerosol modes are controlled by the concentrations of the relevant species in each mode. The large differences observed for $\mathrm{HNO}_{3}$ and $\mathrm{HCl}$ over the sea-salt mode, and $\mathrm{NH}_{3}$ over the non-sea-salt mode, are caused by the high concentrations of these species in the relevant condensed phases, meaning that these species take longer to regain equilibrium with the gas phase after any perturbation from this state (see Sander, 1999, for a detailed explanation of this phenomena). The small differences between the partial and vapor pressures observed for $\mathrm{NH}_{3}$ over the sea-salt mode, and $\mathrm{HNO}_{3}$ and $\mathrm{HCl}$ over the non-sea-salt mode, are, conversely, due to the low concentration of these species in the relevant condensed phases. 
[45] This simulation demonstrates the ability of PD-FiTE to be used stably in dynamical simulations of multicomponent aerosol evolution in a changing gaseous environment.

\section{Discussion and Conclusions}

[46] Here we have presented the hybrid Partial Derivative Fitted Taylor Expansion (PD-FiTE) activity coefficient method designed from calculating the equilibrium vapor pressure of key semivolatile inorganic species above an aqueous aerosol, namely $\mathrm{HNO}_{3}, \mathrm{HCl}$ and $\mathrm{NH}_{3}$. PD-FiTE uses a complex thermodynamic model to derive "optimized" interaction parameters between solutes in solution resulting in comparable computational performance with existing reduced methods, while remaining accurate. While some methods neglect interactions between solutes, assuming binary behavior, in this study comparisons with a benchmark inorganic model (The Pitzer, Simonson and Clegg mole fraction model (PSC)) and an existing mixing rule (The multicomponent Taylor series expansion method (MTEM)) suggest that the coupled approach used in PD-FiTE can capture solution nonideality, thus equilibrium vapor pressures, very well across both sulfate-rich and sulfate-poor compositions. To ensure this, the model parameters were fit to the entire composition space of the system $\mathrm{H}^{+}-\mathrm{NH}_{4}^{+}-\mathrm{Na}^{+}-$ $\mathrm{SO}_{4}^{2-}-\mathrm{HSO}_{4}^{-}-\mathrm{NO}_{3}^{-}-\mathrm{Cl}^{-}$at $298.15 \mathrm{~K}$. This was shown to preserve the ability to capture the dissociation of the bisulfate ion implicitly in model parameters. The linear additive framework of PD-FiTE allows the inclusion of further species, including the ability to exploit data describing the interaction between inorganic and organic components as it becomes available. To demonstrate its use and applicability, this framework was then coupled with a combined chemistrymicrophysical aerosol box model and used in a simple test case investigating the response of a marine aerosol distribution passing through a polluted environment. The particle phase is composed of two externally mixed modes: a nonsea-salt mode with dry composition $32 \%\left(\mathrm{NH}_{4}\right)_{2} . \mathrm{SO}_{4}, 64 \%$ $\mathrm{NH}_{4} \cdot \mathrm{HSO}_{4}$, and $2 \% \mathrm{NH}_{4} \cdot \mathrm{NO}_{3}$; and a sea-salt mode with a dry composition of $100 \% \mathrm{NaCl}$. Results show the robustness of PD-FiTE and illustrates its usefulness in capturing the fine details of important phenomena such as the out gassing of $\mathrm{HCl}$ in response to $\mathrm{HNO}_{3}$ uptake by sea-salt particles.

\section{Appendix A}

[47] This appendix details the calculations made to derive the relative computation costs of PD-FiTE and MTEM for the test case described in section 6.3. These costs will be given in terms of floating point operations (FLOPS): each multiplication and addition performed costs 1 FLOP, as does each division (where we divide by more than one variable we will deal with the multiplication or addition of those variables first, then calculate the cost of the division). From the inputs of water activity ( $\mathrm{a}_{\mathrm{w}}$; equivalent to the relative humidity) and moles of the ions $\mathrm{H}^{+}, \mathrm{Na}^{+}, \mathrm{NH}_{4}^{+}, \mathrm{SO}_{4}^{2-}, \mathrm{NO}_{3}^{-}$, and $\mathrm{Cl}^{-}$, we will calculate the logs of the activity coefficients used for calculating the vapor pressures of $\mathrm{HNO}_{3}, \mathrm{HCl}$, and $\mathrm{NH}_{3}$, and the bisulfate dissociation constant. The cost of converting the log values will not be considered in this analysis. The cost of considering the $\mathrm{Ca}^{2+}$ ion in MTEM will not be considered in this analysis, or the cost of determining any of the extra activity coefficients that MTEM deals with, in order that we can compare like with like. For this reason we will also calculate the logs of the activity coefficients for determining the vapor pressure of $\mathrm{NH}_{3}$ in the sulfate-poor domain. Zaveri et al. [2005] do not discuss how this is to be calculated, so instead we have used the approach described in Zaveri et al. [2008], who, in certain sulfate-poor regions, substitute the activity coefficients of $\mathrm{NH}_{4} \mathrm{NO}_{3}$ and $\mathrm{HNO}_{3}$ into the $\mathrm{NH}_{3}$ vapor pressure calculation [cf. Zaveri et al., 2008, equation (50)].

[48] The test case used involves an external time step, with fixed $\mathrm{RH}$, within which are 10 internal time steps, during each of which the composition of the 8 aerosol size bins change. The computational costs for PD-FiTE and MTEM will, therefore, be broken down into the following four categories.

[49] EX1. At the start of the external time step the partial derivatives and $\operatorname{logs}$ of the binary activity coefficients are calculated. These calculations are of the form shown in equation (19), of this paper, and for a fifth-order polynomial (such as those used by Zaveri et al. [2005]) would cost 20 FLOPs each.

[50] IN1. At the start of each internal time step. For MTEM, the relative amounts of the different electrolytes in each aerosol size bin are calculated. First the sulfate domain of the liquid aerosol (using the work of Zaveri et al. [2005, equation (8)]) is determined. For a sulfate-poor aerosol we then use the work of Zaveri et al. [2005, equations (9) and (10)] to determine the electrolyte partitioning. Whereas for a sulfate-rich aerosol we would use the ratios described in equation (18), and the calculations given in Table 2 of the same paper. For PD-FiTE we need only calculate the ion pairings $\mathrm{N}_{\mathrm{E}, \mathrm{M}} \mathrm{N}_{\mathrm{E}, \mathrm{X}}$ at this point.

[51] IN2. We now sum the electrolyte concentrations for MTEM, and the ion pairings for PD-FiTE (equation (14)).

[52] IN3. Finally the logs of the required activity coefficients are calculated using the equivalent mole fractions and $\operatorname{logs}$ of the binary activity coefficients calculated previously, for PD-FiTE we use equation (15) of this paper, while the calculations for MTEM use equation (9) [Zaveri et al., 2005, equation (6)].

[53] The computational costs of PD-FiTE are:

[54] EX1. The partial derivatives for $\mathrm{HNO}_{3}, \mathrm{HCl}, \mathrm{NH}_{3}$, $\mathrm{HHSO}_{4}$ and $\mathrm{H}_{2} \mathrm{SO}_{4}$ for each possible electrolyte combination in the solution (for PD-FiTE this is $\mathrm{HCl}, \mathrm{HNO}_{3}, \mathrm{H}_{2} \mathrm{SO}_{4}$, $\left(\mathrm{NH}_{4}\right)_{2} \mathrm{SO}_{4}, \mathrm{NH}_{4} \mathrm{NO}_{3}, \mathrm{NH}_{4} \mathrm{Cl}, \mathrm{Na}_{2} \mathrm{SO}_{4}, \mathrm{NaNO}_{3}$ and $\mathrm{NaCl}$ ) are calculated for the given relative humidity. The binary activity coefficients for $\mathrm{HNO}_{3}, \mathrm{HCl}, \mathrm{HHSO}_{4}$, and $\mathrm{H}_{2} \mathrm{SO}_{4}$ are also calculated at this point. The total costs of calculating these polynomials (which are given in Tables 3 and 5) are $566,598,475$, and 457 FLOPS in the relative humidity ranges of $10-20 \%, 20-40 \%, 40-90 \%$ and $90-99 \%$ respectively.

[55] IN1. The total cost of calculating the 9 different ion pairings listed above is 9 FLOPS.

[56] IN2. The total cost of summing the 9 different ion pairings listed above is 17 FLOPS.

[57] IN3. The total cost of calculating the logs of the activity coefficients for $\mathrm{HNO}_{3}, \mathrm{HCl}, \mathrm{NH}_{3}, \mathrm{HHSO}_{4}$ and $\mathrm{H}_{2} \mathrm{SO}_{4}$ is 86 FLOPs.

[58] The total computational cost per size bin per internal time step is 102 FLOPS, which is multiplied by the 8 size bins and 10 internal time step iterations. For the entire external 
time step the total costs are, therefore $8726,8758,8635$, and 8617 FLOPS in the relative humidity ranges of $10-20 \%$, $20-40 \%, 40-90 \%$ and $90-99 \%$ respectively.

[59] The computational costs of MTEM are:

[60] EX1. The partial derivatives for $\mathrm{HNO}_{3}, \mathrm{HCl}, \mathrm{NH}_{3}$, $\mathrm{NH}_{4} \mathrm{NO}_{3}, \mathrm{HHSO}_{4}$ and $\mathrm{NH}_{4} \mathrm{SO}_{4}$ for each possible electrolyte combination, in both the sulfate-rich and sulfate-poor domains, are calculated for the given relative humidity. The total cost of calculating these polynomials (which are given in the work of Zaveri et al. [2005, Tables 4 and 5]) is 1,220 FLOPS.

[61] IN1. We begin each internal time step by calculating the sulfate domain, at a cost of 2 FLOPS. The costs of calculating the relative amounts of electrolytes are then 66,17 , and 9 FLOPS in the domains of $\mathrm{Xt}>2,1<\mathrm{Xt}<2$, and $\mathrm{Xt}<1$ respectively.

[62] IN2. The total costs of summing up the total amount of these electrolytes are 23, 17, and 14 FLOPS in the domains of $\mathrm{Xt}>2,1<\mathrm{Xt}<2$, and $\mathrm{Xt}<1$ respectively.

[63] IN3. The total costs of calculating the logs of the relevant activity coefficients are $48,44,52$, and 42 FLOPS in the domains of $\mathrm{Xt}>2,1.5<\mathrm{Xt}<2,1<\mathrm{Xt}<1.5$ and $\mathrm{Xt}<1$ respectively.

[64] The total computational costs per size bin per internal time step are, therefore, 139, 80, 88, and 67 FLOPS in the domains of $\mathrm{Xt}>2,1.5<\mathrm{Xt}<2,1<\mathrm{Xt}<1.5$ and $\mathrm{Xt}<1$ respectively. For the entire external time step the total costs are, therefore $12340,7620,8260$, and 6580 FLOPS in the domains of $\mathrm{Xt}>2,1.5<\mathrm{Xt}<2,1<\mathrm{Xt}<1.5$ and $\mathrm{Xt}<1$ respectively.

\section{Notation}

$\gamma_{i}^{o} \quad$ binary molal activity coefficient of specie " $\mathrm{i}$ ".

$\gamma_{i}$ mean binary molal activity coefficient of specie "i"

$c_{a}$ concentration of a chemical species in the condensed phase

$c_{i}^{\prime} \quad$ a variable which defines the contribution of species " $i$ " to the value of $y$

$d^{\prime}{ }_{i j}$ an interaction parameter between component "i" and " $j$ "

$f_{i}$ mole fraction based activity coefficient of compound "i"'

$K_{M X} \quad$ Henry's law constant of specie MX

$k_{t}$ mass transfer coefficient

$M_{i} \quad$ mass of the solute present

$m_{M}$ molality of the ion $\mathrm{M}^{+}(\mathrm{mol} / \mathrm{kg})$

$m_{X}$ molality of the ion $\mathrm{M}(\mathrm{mol} / \mathrm{kg})$

$N_{i}$ number of moles of specie "i".

$P_{i}, \infty$ partial pressure of the chemical species " $\mathrm{i}$ " in the gas phase (atm)

$P_{i}$ equilibrium pressure of component " $i$ " over a solution (atm)

$P_{i}^{o} \quad$ saturation pressure of component " $i$ ", or pure component vapor pressure (atm)

$v$ ionic stoichiometry of species MX

$\mathrm{V}_{\mathrm{M}(\mathrm{X})}$ stoichiometric coefficient of component $\mathrm{M}$ in the salt $\mathrm{N}_{\mathrm{MX}}$

$W$ total water content associated with a particle

$X_{T}$ the sulfate ratio

$X_{i}$ mole fraction of component " $\mathrm{i}$ " in solution.

$x_{i}$ a representation of the amount of species " $i$ " $y$ a variable being parameterized

$\mathrm{Z}_{\mathrm{M}}$ the charge on component $\mathrm{M}$

[65] Acknowledgment. The authors would like to thank Michael Bane of the University of Manchester and anonymous referees for their useful input.

\section{References}

Ansari, A. S., and S. N. Pandis (1999), Prediction of multicomponent inorganic atmospheric aerosol behavior, Atmos. Environ., 33(5), 745757.

Bromley, L. A. (1973), Thermodynamic properties of strong electrolytes in aqueous-solutions, AIChE J., 19, 313-320.

Chameides, W. L. (1984), The photochemistry of a remote marine stratiform cloud, J. Geophys. Res., 89(D3), 4739-4755.

Clegg, S. L., and J. H. Seinfeld (2006), Thermodynamic models of aqueous solutions containing inorganic electrolytes and dicarboxylic acids at 298.15 K. 1: The acids as nondissociating components, J. Phys. Chem. A, 110, 5692-5717.

Clegg, S. L., K. S. Pitzer, and P. Brimblecombe (1992), Thermodynamics of multicomponent, miscible, ionic-solutions. 2: Mixtures including unsymmetrical electrolytes, J. Phys. Chem., 96, 9470-9479.

Clegg, S. L., S. Milioto, and D. A. Palmer (1996), Osmotic and activity coefficients of aqueous $\left(\mathrm{NH}_{4}\right)_{2} \mathrm{SO}_{4}$ as a function of temperature, and aqueous $\left(\mathrm{NH}_{4}\right)_{2} \quad \mathrm{SO}_{4}-\mathrm{H}_{2} \mathrm{SO}_{4}$ mixtures at $298.15 \mathrm{~K}$ and $323.15 \mathrm{~K}$, J. Chem. Eng. Data, 41(3), 455-467.

Clegg, S. L., P. Brimblecombe, and A. S. Wexler (1998a), Thermodynamic model of the system $\mathrm{H}^{+}-\mathrm{NH}_{4}^{+}-\mathrm{Na}^{+}-\mathrm{SO}_{4}^{2-}-\mathrm{NO}_{3}^{-}-\mathrm{Cl}^{-}-\mathrm{H}_{2} \mathrm{O}$ at $298.15 \mathrm{~K}$, J. Phys. Chem. A, 102, 2155-2171.

Clegg, S. L., P. Brimblecombe, and A. S. Wexler (1998b), Thermodynamic model of the system $\mathrm{H}^{+}-\mathrm{NH}_{4}^{+}-\mathrm{SO}_{4}^{2-}-\mathrm{NO}_{3}^{-}-\mathrm{H}_{2} \mathrm{O}$ at tropospheric temperatures, J. Phys. Chem. A, 102, 2137-2154.

Clegg, S. L., J. H. Seinfeld, and P. Brimblecombe (2001), Thermodynamic modelling of aqueous aerosols containing electrolytes and dissolved organic compounds, J. Aerosol Sci., 32, 713-738.

Damian, V., A. Sandu, M. Damian, F. Potra, and G. R. Carmichael (2002), The kinetic preprocessor KPP_A software environment for solving chemical kinetics, Comput. Chem. Eng., 26, 1567-1579.

Jacobson, M. Z. (1997), Development and application of a new air pollution modeling system. 2: Aerosol module structure and design, Atmos. Environ., $31,131-144$.

Jacobson, M. Z. (1999), Fundamentals of Atmospheric Modeling, Cambridge Univ. Press, 656 pp.

Jacobson, M. Z., A. Tabazadeh, and R. P. Turco (1996), Simulating equilibrium within aerosols and nonequilibrium between gases and aerosols, J. Geophys. Res., 101(D4), 9079-9091.

Kusik, C. L., and H. P. Meissner (1978), Electrolyte activity coefficients in inorganic processing, AIChe Symp. Ser, 173, 14-20.

Marcolli, C., B. P. Luo, and T. Peter (2004), Mixing of the organic aerosol fractions: Liquids as the thermodynamically stable phases, J. Phys. Chem. A, 108(12), 2216-2224.

Marti, J. J., A. Jefferson, X. P. Cai, C. Richert, P. H. McMurry, and F. Eisele (1997), $\mathrm{H}_{2} \mathrm{SO}_{4}$ vapor pressure of sulfuric acid and ammonium sulfate solutions, J. Geophys. Res., 102(D3), 3725-3735.

Metzger, S., F. Dentener, M. Krol, A. Jeuken, and J. Lelieveld (2002a), Gas/ aerosol partitioning: 2. Global modeling results, J. Geophys. Res., 107(D16), 4313, doi:10.1029/2001JD001103.

Metzger, S., F. Dentener, S. Pandis, and J. Lelieveld (2002b), Gas/aerosol partitioning: 1. A computationally efficient model, J. Geophys. Res., 107(D16), 4312, doi:10.1029/2001JD001102.

Ming, Y., and L. M. Russell (2002), Thermodynamic equilibrium of organicelectrolyte mixtures in aerosol particles, AIChE J., 48, 1331-1348.

Nenes, A., S. N. Pandis, and C. Pilinis (1998), ISORROPIA: A new thermodynamic equilibrium model for multiphase multicomponent inorganic aerosols, Aquat. Geochem., 4, 123-152.

Pitzer, K. S., and J. M. Simonson (1986), Thermodynamics of multicomponent, miscible, ionic systems: Theory and equations, J. Phys. Chem., 90, 3005-3009.

Reilly, P. J., and R. H. Wood (1969), The prediction of the properties of mixed electrolytes from measurements on common ion mixtures, J. Phys. Chem., 73, 4292-4297.

Seinfeld, J. H., and S. N. Pandis (1998), Atmospheric Chemistry and Physics. From Air Pollution to Climate Change, Wiley-Interscience, Hoboken, N. J.

Solomon, S., D. Qin, M. Manning, M. Marquis, K. Averyt, M. M. B. Tignor, and H. L. J. Miller (2007), IPCC, Summary for Policymakers (SPM), in Climate Change 2007-The Physical Science Basis. Contribution of Working Group 1 to the Fourth Assessment Report of the Intergovernmental Panel on Climate Change, edited by S. Solomon et al., Cambridge Univ. Press, New York. 
Stokes, R. H., and R. A. Robinson (1966), Interactions in aqueous nonelectrolyte solutions. I: Solute-Solvent equilibria, J. Phys. Chem., 70, $2126-2131$.

Topping, D. O., G. B. McFiggans, and H. Coe (2005a), A curved multicomponent aerosol hygroscopicity model framework. Part 1: Inorganic compounds, Atmos. Chem. Phys., 5, 1205-1222.

Topping, D. O., G. B. McFiggans, and H. Coe (2005b), A curved multicomponent aerosol hygroscopicity model framework. Part 2: Including organic compounds, Atmos. Chem. Phys., 5, 1223-1242.

Wagman, D. D., W. H. Evans, V. B. Parker, I. H. Schumm, S. M. Bailey, K. L. Churney, and R. L. Nuttall (1982), The NBS tables of chemical thermodynamics properties, J. Phys. Chem. Ref. Data, 11, 392.

Weast, R. C. (Ed.) (1980), CRC Handbook of Chemistry and Physics, 61st ed., CRC Press, Boca Raton, Fla.

Wexler, A. S., and S. L. Clegg (2002), Atmospheric aerosol models for systems including the ions $\mathrm{H}^{+}, \mathrm{NH}_{4}^{+}, \mathrm{Na}^{+}, \mathrm{SO}_{4}^{2-}, \mathrm{NO}_{3}^{-}, \mathrm{Cl}^{-}, \mathrm{Br}^{-}$, and $\mathrm{H}_{2} \mathrm{O}$, J. Geophys. Res., 107(D14), 4207, doi:10.1029/2001JD000451.
Zaveri, R. A., R. C. Easter, and A. S. Wexler (2005), A new method for multicomponent activity coefficients of electrolytes in aqueous atmospheric aerosols, J. Geophys. Res., 110, D02201, doi:10.1029/2004JD004681.

Zaveri, R. A., R. C. Easter, J. D. Fast, and L. K. Peters (2008), Model for simulating aerosol interactions and chemistry (MOSAIC), J. Geophys. Res., 113, D13204, doi:10.1029/2007JD008782.

D. Lowe and G. McFiggans, School of Earth, Atmospheric and Environmental Science, University of Manchester, Room 3.13, Simon Building, Oxford Road, Manchester M13 9PL, UK.

D. Topping, Composition Directorate, National Centre for Atmospheric Science, School of Earth, Atmospheric and Environmental Science, University of Manchester, Room 3.13, Simon Building, Oxford Road, Manchester M13 9PL, UK. (david.topping@manchester.ac.uk) 